Artigo

\title{
Variabilidade Interanual da Precipitação e Fluxo de Umidade Sobre a Amazônia Usando o QTCM
}

\author{
Aline Corrêa de Sousa ${ }^{1}$ iD , Luiz Antonio Candido ${ }^{2}$ iD, Rita Valéria Andreoli ${ }^{3}$ iD \\ ${ }^{1}$ Programa de Pós-Graduação em Clima e Ambiente, \\ Instituto Nacional de Pesquisas da Amazônia, Manaus, AM, Brasil. \\ ${ }^{2}$ Coordenação de Dinâmica Ambiental, Instituto Nacional de Pesquisas da Amazônia, \\ Manaus, AM, Brasil. \\ ${ }^{3}$ Escola Superior de Tecnologia, Universidade do Estado do Amazonas, Manaus, AM, Brasil.
}

Recebido em 14 de Fevereiro de 2017 - Aceito em 11 de Abril de 2017

\begin{abstract}
Resumo
O objetivo deste trabalho foi avaliar a resposta atmosférica aos padrões de variabilidade interanual da Temperatura da Superfície do Mar nas áreas dos oceanos Atlântico e Pacífico Tropicais, analisando o ciclo sazonal da Divergência de Fluxo de Umidade, sobre as regiões do Atlântico Tropical Norte e Sul e Amazônia. Os dados de Reanálise foram utilizados no estudo observacional e para o estudo numérico foi utilizado o Quasi-equilibrium Tropical Circulation Model - QTCM. Os resultados mostram que o QTCM tem habilidade na representação da distribuição espacial dos máximos de precipitação sobre o continente e suas variações sazonais. O QTCM reproduz os padrões climatológicos da precipitação e de Divergência de Fluxo de Umidade associados à ocorrência de eventos El Niño Oscilação Sul e Modo Meridional do Atlântico, sugerindo também que o comportamento médio sazonal da Divergência de Fluxo de Umidade, na área Norte do Atlântico, tem maior impacto na ocorrência de $E l$ Niño, induzindo a redução da precipitação na Amazônia. A área Norte do Atlântico além de fonte de umidade é também um importante regulador da Divergência de Fluxo de Umidade, cujas anomalias de temperatura nessa região proporcionam impactos sobre a parte Norte da América do Sul e Amazônia.
\end{abstract}

Palavras-chave: fontes de umidade, divergência de fluxo de umidade, QTCM.

\section{Interannual Variability of Precipitation and Moisture Flux on Amazon Using QTCM}

\begin{abstract}
The aim of this study was to evaluate the atmospheric response to the interannual variability patterns of Sea Surface Temperature in the areas of the Atlantic and Tropical Pacific, analyzing the seasonal cycle of Moisture Flux Divergence on the regions of the North and South Atlantic Tropical and Amazon. The Reanalysis data were used in the observational study, and the numerical study used the Quasi-equilibrium Tropical Circulation Model - QTCM. The results show that QTCM has ability to represent the spatial distribution of precipitation maximum on the continent and its seasonal variations. QTCM plays the climatological patterns of precipitation and Moisture Flux Divergence associated with the occurrence of El Niño Southern Oscillation and Atlantic Meridional Mode, also suggesting that the seasonal average behavior of Moisture Flux Divergence in North Atlantic area, it has greater impact on the occurrence of El Niño, leading to reduced precipitation in the Amazon. North Atlantic area beyond the source of moisture is also an important regulator of Moisture Flux Divergence, whose temperature anomalies in this region provide impacts on the northern part of South America and Amazon.
\end{abstract}

Keywords: moisture sources, moisture flux divergence, QTCM.

Autor de correspondência: Aline Corrêa de Sousa, e-mail: alinecorrea.acs@gmail.com. 


\section{Introdução}

A variabilidade interanual da Temperatura da Superfície do Mar (TSM) nas áreas dos oceanos Pacífico Equatorial e Atlântico Tropical, associada aos fenômenos El Niño, La Niña, ou a variabilidade no oceano Atlântico Tropical Norte (ATN) e Atlântico Tropical Sul (ATS), tem forte influência no balanço hídrico e clima regional da América do Sul (Uvo et al., 2000). Estes eventos afetam o ciclo anual das chuvas e vazões em algumas das principais bacias hidrográficas da América do Sul, tais como as do rio Amazonas e rio São Francisco, acarretando em reduções acentuadas da precipitação, ocasionando, por exemplo, as grandes estiagens ocorridas em 1926, 1983, 1998, 2005 e 2010 (Marengo e Dias, 2006; Marengo et al., 2008a, 2008b, 2011; Zeng et al., 2008; Chen et al., 2009; Espinoza et al., 2011; Lewis et al., 2011), como também favorecendo aumentos na precipitação, que levaram as grandes cheias de 2009 e 2012 na Amazônia (Satyamurty et al., 2013b).

O fenômeno El Niño Oscilação Sul (ENOS) sobre o Pacífico Equatorial modula grande parte da variabilidade interanual da precipitação sobre a América do Sul (Grimm, 2003 e 2004; Andreoli e Kayano, 2007; Grimm e Zilli, 2009; Kayano et al., 2011 e 2013). As circulações atmosféricas influenciadas pelo padrão anômalo de TSM sobre os oceanos afetam o posicionamento latitudinal da Zona de Convergência Intertropical (ZCIT) sobre o Atlântico e continente adjacente, impactando a distribuição das chuvas sobre a bacia do Atlântico e Norte da América do Sul (Kousky et al., 1984; Nobre e Shukla, 1996; Yoon e Zeng, 2010; Kayano et al., 2011 e 2013).

A influência do Atlântico Tropical sobre a precipitação na América do Sul se estabelece também pela sua contribuição no fornecimento de umidade para o continente oriunda de suas porções ao Norte e ao Sul (Uvo et al., 2000; Liebmann e Marengo, 2001; Marshall et al., 2001; Ronchail et al., 2002; Drumond et al., 2008, 2014; Gimeno et al., 2010, 2012, 2013; Yoon e Zeng, 2010; Trenberth et al., 2011; Satyamurty et al., 2013a; van der Ent e Savenije, 2013). Entretanto, o impacto na disponibilidade de água para atmosfera a partir destas áreas oceânicas ainda não é ressaltado.

O aumento da intensidade da TSM no ATN, por exemplo, foi um dos fatores responsáveis pela seca intensa ocorrida no ano 2005 na Amazônia, que se mostrou com padrão diferente da maioria das secas relacionadas normalmente ao El Niño (Marengo et al., 2008b; Zeng et al., 2008). Embora a variabilidade interanual da TSM no Atlântico Tropical seja significativamente menor do que a observada no Pacífico Equatorial (Marshall et al., 2001; Ronchail et al., 2002; Yoon e Zeng, 2010; Kayano et al., 2013), sua influência na variabilidade da precipitação sobre a América do Sul é importante, particularmente na porção leste da Amazônia (Nobre e Shukla, 1996) e Nordeste do Brasil (Andreoli e Kayano, 2007; Moura e Shukla, 1981;
Nobre e Shukla, 1996); e extremo sul do Brasil e Uruguai (Diaz e Studzinski, 1994).

Essa influência do Atlântico Tropical em eventos de seca na Amazônia sugere que impactos no fornecimento de umidade para atmosfera e seu transporte para o continente através dos ventos alísios de nordeste estão interligados e precisam ser quantificados em comparação aos impactos na circulação atmosférica. O uso de modelos climáticos que representem os mecanismos essenciais e incorporem os processos físicos é uma alternativa para o entendimento das relações entre o sistema climático regional, os oceanos e continente.

O Modelo de Circulação Tropical de Quasi-equilíbrio (QTCM, sigla em inglês), desenvolvido pelo Department of Atmospheric Sciences UCLA, por J. David Neelin e Ning Zeng (Neelin e Zeng, 2000), foi proposto como um ponto de referência para a comparação sistemática com resultados de modelos mais complexos e para mostrar que este reproduz qualitativamente a climatologia das características gerais da atmosfera tropical. O QTCM tem sido útil para uma série de estudos de modelagem, variabilidade intrasazonal e teleconexões atmosféricas na região dos trópicos (Chiang e Sobel, 2002; Neelin e Su, 2005; Neelin e Zeng, 2000; Gushchina et al., 2006; Lintner e Chiang, 2007; Lintner et al., 2012; Sobel e Neelin, 2006; Su e Neelin, 2002; Zeng et al., 2000). Uma descrição detalhada do modelo pode ser encontrada em Neelin e Zeng (2000).

Claramente o uso do QTCM em simulações idealizadas reproduzindo condições de importantes fenômenos de diferentes escalas temporais de variabilidade na região tropical, tais como ENOS, Oscilação Multidecadal do Atlântico, Oscilação Decadal do Pacífico, entre outros, amplia sua aplicabilidade em estudos de muitos problemas climáticos. O QTCM contém os elementos essenciais necessários para o estudo da dinâmica da atmosfera tropical, e alguns desses processos são avaliados neste trabalho, considerando séries de dados observacionais e de Reanálise, além de eventos climáticos importantes associados ao ENOS e ao Modo Meridional do Atlântico - MMA (Servain, 1991; Enfield e Mayer,1997; Kayano et al., 2005).

Neste sentido, este trabalho tem como objetivo avaliar a resposta atmosférica aos padrões de variabilidade interanual da TSM nas áreas dos oceanos Attântico e Pacífico Tropicais, simulados pelo QTCM, comparando-a à resposta atmosférica a partir de séries de dados observacionais e de Reanálise, analisando o ciclo sazonal e interanual da precipitação tropical e da Divergência de Fluxo de Umidade, doravante chamada de DFU, sobre as regiões no oceano Atlântico Tropical e sobre a Amazônia.

\section{Material e Métodos}

\subsection{Bases de dados}

As análises desenvolvidas neste trabalho se basearam em várias séries de dados observacionais, e em simulações 
com um modelo climático de complexidade intermediária. Para as condições oceânicas foram usados campos globais mensais de TSM reconstruídos de Smith et al. (2008), versão 3 , na resolução horizontal de $2^{\circ} \times 2^{\circ}$, no período 1950 a 2013. Esses dados foram utilizados como condições de contorno do modelo.

Ainda, séries mensais de precipitação global provenientes da base de dados Global Precipitation Climatology Project (GPCP), versão 2.2, (Adler et al., 2003), além das séries temporais mensais de umidade específica, componentes zonal e meridional do vento obtidas da Reanálise do NCEP/NCAR (National Center for Environmental Prediction e National Center for Atmospheric Research) (Kalnay et al., 1996), ambos conjuntos com resolução de $2,5^{\circ} \times 2,5^{\circ}$, foram utilizadas na definição dos padrões sazonais e de variabilidade da precipitação para o período de 1979 a 2013 (período de disponibilidade dos dados) e do transporte de umidade horizontal, durante o período 1950 a 2013, observados a fim de compara-los com os resultados simulados pelo QTCM.

\subsection{Balanço de umidade atmosférica}

$\mathrm{Na}$ estimativa do transporte horizontal de umidade e suas condições de convergência e divergência de umidade, foi utilizado o princípio da conservação de massa para o vapor d'água, na determinação do balanço de umidade na atmosfera segundo a Eq. (1):

$$
\frac{d W}{d t}=-P+E+C
$$

onde $P$ e $E$ representam a perda e o ganho de umidade da atmosfera por precipitação e evaporação, respectivamente, e $\frac{d W}{d t}$ representa o termo de variação do conteúdo de umidade na atmosfera, e $C$ representa a convergência do fluxo de umidade integrado verticalmente na coluna atmosférica, determinada pela Eq. (2):

$$
C=-\nabla(q \boldsymbol{V})=-\left[\frac{\partial(q u)}{\partial x}+\frac{\partial(q v)}{\partial y}\right]
$$

No cálculo do balanço de umidade atmosférico médio anual, o termo de variação do estoque foi muito pequeno comparado às outras componentes e, portanto, foi desprezado de forma semelhante ao que foi feito por Zeng (1999). Deste modo, podemos considerar a seguinte expressão:

$$
\mathrm{DFU}=-\nabla(q \boldsymbol{V})=E-P
$$

A Eq. (3) reflete com boa aproximação a dinâmica do balanço entre a divergência do fluxo de umidade na atmosfera e seus termos fonte e sumidouro de umidade. Esta expressão indica que se a divergência de umidade é positiva, a evaporação é maior que a precipitação (a região é uma área fonte de umidade, $E-P>0$ ), e se a divergência de umidade é negativa, a precipitação é maior que a evaporação (a região é sumidouro de umidade, $E-P<0$ ).
A DFU foi determinada integrando-se as componentes (zonal e meridional) do fluxo de umidade na atmosfera desde a superfície até $300 \mathrm{mb}$, com base nos dados de Reanálise, sobre as áreas oceânicas e sobre o continente, segundo as coordenadas $\left(2^{\circ}-12^{\circ} \mathrm{N}, 55^{\circ}-35^{\circ} \mathrm{W}\right.$, ATN; $4^{\circ}$ $14^{\circ} \mathrm{S}, 37^{\circ}-17^{\circ} \mathrm{W}$, ATS; $18^{\circ} \mathrm{S}-4^{\circ} \mathrm{N}, 75^{\circ}-50^{\circ} \mathrm{W}$, Amazônia). O cálculo da divergência envolveu a estimativa do fluxo de umidade através dos segmentos de linhas delimitados pelas coordenadas das áreas e definidoras de suas bordas. O fluxo nessas secções laterais foi integrado verticalmente e ao longo de cada segmento do perímetro das áreas para fornecer o fluxo líquido de umidade através da somatória dos fluxos de entrada e saída.

\subsection{Condições anômalas dos oceanos}

Para avaliar a influência das condições anômalas de TSM dos oceanos foi aplicada a técnica de composição (Hoerling et al., 1997), tanto nos dados observacionais, quanto nos dados das simulações, considerando anos de ocorrência de eventos ENOS (El Niño e La Niña) e anos de ocorrência de eventos MMA (MMA+ e MMA-). A seleção dos anos de eventos ENOS foi realizada a partir dos índices de anomalias de TSM na região Niño $3.4\left(5^{\circ} \mathrm{N}-5^{\circ} \mathrm{S}\right.$, $120^{\circ} \mathrm{W}-170^{\circ} \mathrm{W}$ ) segundo os critérios de Trenberth (1997). Portanto, para selecionar um ano inteiro como El Niño ou La Niña, foram considerados aqueles anos em que o limiar foi superado um mínimo de cinco vezes consecutivas a partir de junho no ano 0 a maio no ano 1 (para um determinado ciclo ENOS).

O índice de MMA foi obtido a partir da diferença entre as médias das anomalias de TSM normalizadas pelo desvio padrão nas respectivas áreas do ATN e ATS para os meses de fevereiro a maio. Anos de MMA+ foram identificados quando ocorreram valores positivos de anomalias de TSM no ATN, e anos de MMA- foram selecionados para valores negativos de anomalias de TSM na área do ATN, segundo o critério de Marengo et al. (2013). Aplicando o mesmo calendário usado para estudar os impactos do ENOS, as diferenças nos compostos foram calculadas em uma escala mensal considerando o ciclo anual de junho do ano 0 a maio no ano 1 .

$\mathrm{Na}$ Tabela 1 têm-se os anos selecionados para os episódios de El Niño, La Niña, MMA+ e MMA-.

As análises foram feitas considerando os campos de precipitação observada para os períodos de Dezembro a Fevereiro (DJF), Março a Maio (MAM), Junho a Agosto (JJA) e Setembro a Novembro (SON). Os padrões de anomalias foram obtidos a partir da diferença entre os compostos relacionados aos eventos quentes e frios do ENOS e do MMA. Assim, conforme Hoerling et al. (1997), os resultados representam a parte linear da resposta climática em relação aos eventos ENOS e MMA. 
Tabela 1 - Anos de ENOS e MMA selecionados durante o período de 1950 a 2013

\begin{tabular}{ccccc}
\hline \multicolumn{2}{c}{ ENOS } & & \multicolumn{2}{c}{ MMA } \\
\cline { 1 - 2 } \cline { 5 - 5 } El Niño & La Niña & & MMA+ & MMA- \\
\hline $1951 / 52 ;$ & $1954 / 55 ;$ & & $1951 / 52 ;$ & $1964 / 65 ;$ \\
$1957 / 58 ;$ & $1955 / 56 ;$ & & $1953 / 54 ;$ & $1965 / 66 ;$ \\
$1963 / 64 ;$ & $1984 / 85 ;$ & & $1956 / 57 ;$ & $1971 / 72 ;$ \\
$1965 / 66 ;$ & $1988 / 89 ;$ & & $1958 / 59 ;$ & $1972 / 73 ;$ \\
$1968 / 69 ;$ & $1995 / 96 ;$ & & $1966 / 67 ;$ & $1973 / 74 ;$ \\
$1972 / 73 ;$ & $1998 / 99 ;$ & & $1970 / 71 ;$ & $1974 / 75 ;$ \\
$1982 / 83 ;$ & $1999 / 00 ;$ & & $1978 / 79 ;$ & $1977 / 78 ;$ \\
$1986 / 87 ;$ & $2000 / 01 ;$ & & $1979 / 80 ;$ & $1983 / 84 ;$ \\
$1987 / 88 ;$ & $2005 / 06 ;$ & & $1980 / 81 ;$ & $1984 / 85 ;$ \\
$1991 / 92 ;$ & $2007 / 08 ;$ & & $1982 / 83 ;$ & $1985 / 86 ;$ \\
$1994 / 95 ;$ & $2008 / 09 ;$ & & $1991 / 92 ;$ & $1988 / 89 ;$ \\
$1997 / 98 ;$ & $2010 / 11 ;$ & & $1996 / 97 ;$ & $1993 / 94 ;$ \\
$2002 / 03 ;$ & $2011 / 12$ & & $2003 / 04 ;$ & $1994 / 95 ;$ \\
$2004 / 05 ;$ & & $2009 / 10$ & $2008 / 09$ \\
$2006 / 07 ;$ & & & \\
$2009 / 10$ & & & \\
\hline
\end{tabular}

\subsection{Simulações climáticas}

O Modelo de Circulação Tropical de Quasi-equilíbrio - QTCM - é um modelo atmosférico tropical de complexidade intermediária, em que a estrutura vertical das variáveis atmosféricas é projetada por um conjunto de funções de base (um para cada variável de temperatura e umidade, e dois para o momentum), empregando-se a discretização vertical Galerkin (Neelin e Zeng, 2000). As parametrizações físicas utilizadas incluem o esquema de transferência radiativa linear de Chou e Neelin (1996), e a convecção Betts-Miller (Betts e Miller, 1986). Os processos da superfície são representados pelo esquema Simple Land de uma camada e com umidade do solo interativa, além dos fluxos de momentum, calor sensível e evaporação. Neste trabalho, utilizou-se a versão 2.3 do QTCM com resolução horizontal de $5.625^{\circ} \times 3.75^{\circ}$. A versão original do modelo não considera a classe de vegetação de caatinga sobre o Nordeste Brasileiro, que precisou ser incorporada juntamente com os parâmetros físicos e delimitação de sua área de abrangência. Estas mudanças foram incorporadas na versão utilizada aqui.

Nas simulações numéricas, o QTCM foi integrado em modo "ensemble" com 10 membros, no período de 1950 a 2013. O conjunto de 10 membros foi obtido a partir de 10 estados iniciais selecionados de uma integração de equilíbrio de 10 anos (1981 a 1990), considerando a TSM climatológica. Da condição equilibrada do último ano de integração foram selecionados os nove dias que antecederam a data inicial (01 de novembro) dos experimentos. A DFU foi estimada nas simulações com o QTCM aplicando-se a aproximação da Eq. (3).

$\mathrm{Na}$ avaliação das simulações considerou-se a análise estatística do "ensemble" médio dos 10 membros para a precipitação considerando as médias para os trimestres de DJF, MAM, JJA e SON. A análise feita aqui é para Ama- zônia em que os índices estatísticos do viés, desvio padrão $(\sigma)$, razão de desvio padrão $\left(R_{\sigma}\right)$, raiz do erro quadrático médio (REQM) e coeficiente de correlação (CC) foram determinados.

\section{Resultados e Discussão}

\subsection{Padrões climatológicos sazonais: modelo vs. observação}

Atenção é dada para o ciclo sazonal dos padrões espaciais de precipitação simulados pelo QTCM em comparação aos respectivos padrões observados.

Na Fig. 1 é mostrada a distribuição espacial média sazonal da precipitação observada e simulada, juntamente com o viés associado ao longo dos trimestres DJF, MAM, JJA e SON.

No trimestre DJF, o modelo simula a banda de nebulosidade associada à Zona de Convergência do Atlântico Sul (ZCAS) sobre o continente da América do Sul, que se estende até o oceano Atlântico Subtropical. A grande banda de precipitação é representada na maior parte da América do Sul tropical, incluindo a região da Amazônia, porém com localização mais ao Norte e taxa média de precipitação mais intensa que a observada (Fig. 1a). Sobre a Amazônia são simulados núcleos de precipitação intensa, associados à convecção e à condensação do ar úmido trazido pelos ventos de Leste, em associação com a posição mais ao Sul da ZCIT, apesar do QTCM não a configurar sobre a porção Norte do Atlântico Tropical. Sobre o Nordeste Brasileiro, o modelo simula chuvas acima do observado (Figs. 1a-1b). O viés mostra que o QTCM superestima a precipitação em até $4 \mathrm{~mm} \cdot \mathrm{dia}^{-1}$ ao longo da costa Norte da América do Sul e subestima em até $-4 \mathrm{~mm} \cdot \mathrm{dia}^{-1}$ no restante do continente e na área do ATN na região da ZCIT (Fig. 1c). A Tabela 2 apresenta os índices estatísticos calculados para a Amazônia para todas as estações.

No trimestre MAM, o padrão de distribuição da precipitação associada ao enfraquecimento das atividades convectivas sobre a região tropical é representado pelo QTCM nas porções Central e Sul da Amazônia (Fig. 1e) em com-

Tabela 2 - Índices estatísticos computados sobre a Amazônia, para todas as estações.

\begin{tabular}{lcccc}
\hline Índices & DJF & MAM & JJA & SON \\
\hline $\bar{P}_{G P C P}\left({\left.\mathrm{~mm} \cdot \mathrm{dia}^{-1}\right)}^{-1}\right.$ & 8,09 & 7,43 & 3,47 & 4,87 \\
$\bar{P}_{\text {QTCM }}\left(\mathrm{mm} \cdot \mathrm{dia}^{-1}\right)$ & 11,15 & 9,98 & 3,60 & 9,48 \\
$\sigma_{G P C P}\left(\mathrm{~mm} \cdot \mathrm{dia}^{-1}\right)$ & 0,66 & 0,51 & 0,34 & 0,38 \\
$\sigma_{\text {QTCM }}\left(\mathrm{mm} \cdot \mathrm{dia}^{-1}\right)$ & 0,44 & 0,31 & 0,50 & 0,26 \\
$R_{\sigma}$ & 1,50 & 1,65 & 0,68 & 1,46 \\
Viés $\left(\mathrm{mm} \cdot \mathrm{dia}^{-1}\right)$ & 3,06 & 2,55 & 0,14 & 4,61 \\
REQM $\left(\mathrm{mm} \cdot \mathrm{dia}^{-1}\right)$ & 3,13 & 2,63 & 0,53 & 4,62 \\
CC & 0,35 & 0,85 & 0,26 & 0,46 \\
\hline
\end{tabular}


paração ao padrão observado (Fig. 1d). Sobre a região Sul e Sudeste do Brasil, a precipitação é subestimada pelo modelo, enquanto que o padrão simulado sobre o Nordeste Brasileiro é próximo do observado (Figs. 1d-f).

O centro de máxima precipitação sobre o continente é deslocado mais para o Norte da América do Sul, em concordância com os padrões observados, durante JJA. Simultaneamente, sobre a região dos oceanos, a precipitação tende a ser enfraquecida no QTCM (Figs. 1g-i).
No trimestre SON, iniciam-se as precipitações que se propagam para Leste e Sudeste da Amazônia Equatorial, de forma semelhante à climatologia observada, onde sistemas precipitantes de grande escala começam a se formar, indicando o início da estação pré-chuvosa, principalmente na Amazônia, apesar da precipitação ser superestimada pelo QTCM (Figs. 1j-1). As porções da ZCIT no Leste do Pacífico e Atlântico Norte são muito fracamente representadas pelo QTCM quando comparadas aos campos climatológicos observados (Fig. 1b).

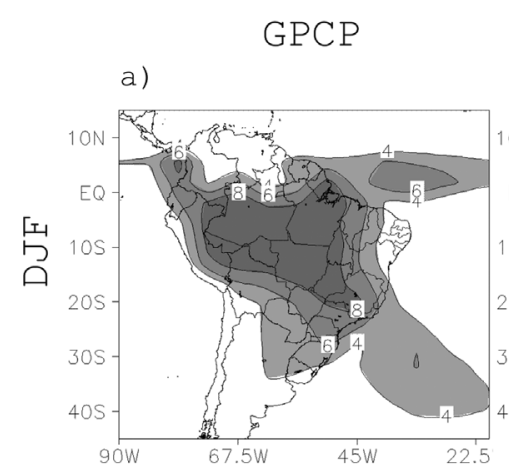

d)

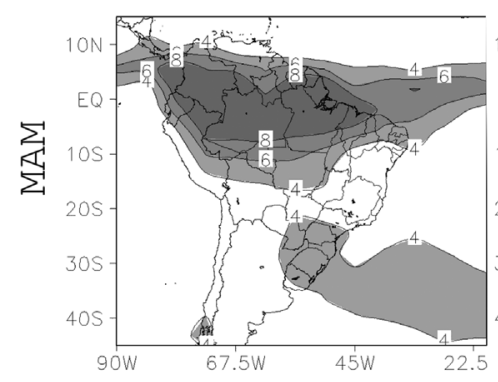

g)

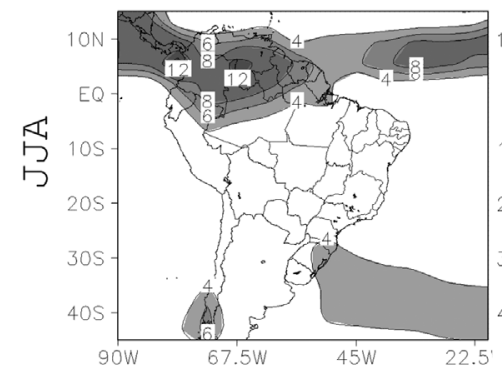

j)

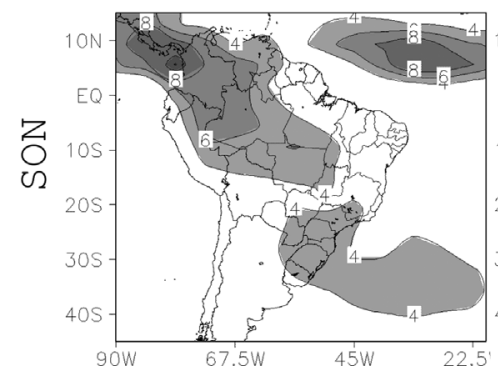

QTCM

b)

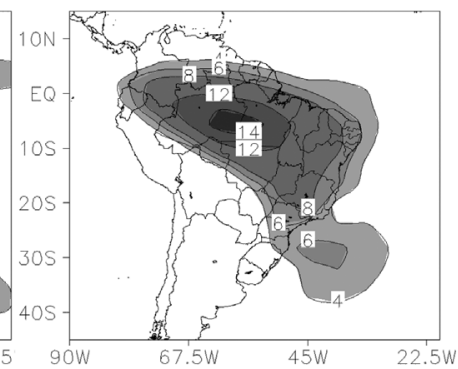

e)

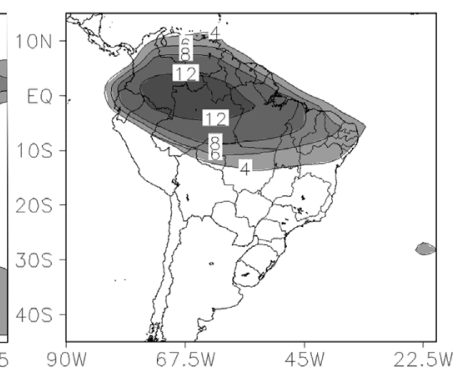

h)

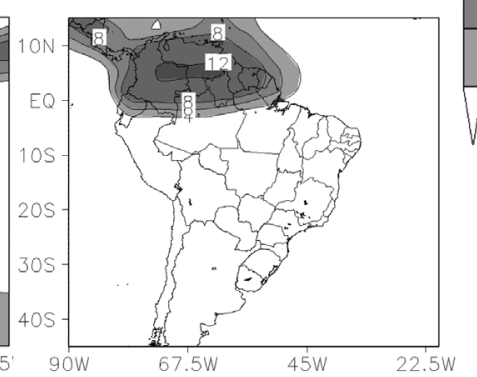

k)

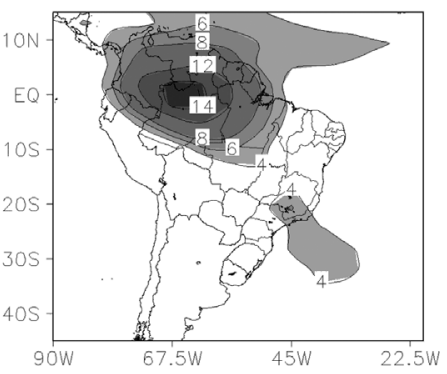

VIÉS

C)

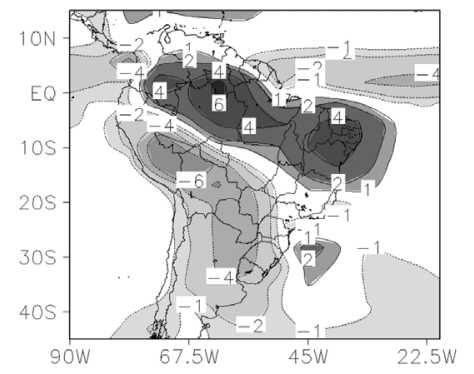

f)

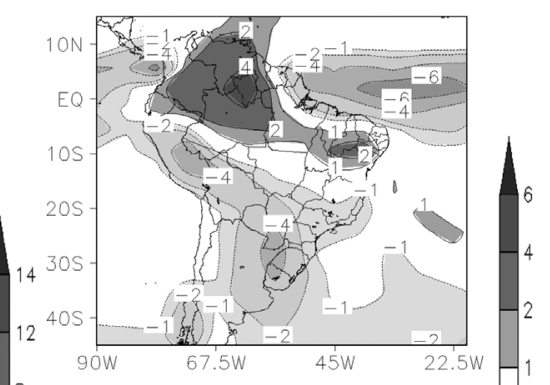

i)

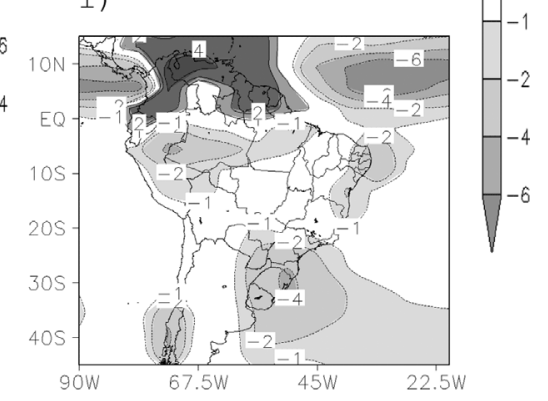

1)

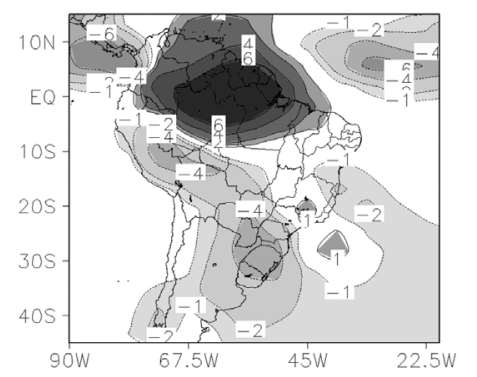

Figura 1 - Distribuição da precipitação média sazonal (mm.dia ${ }^{-1}$ ): observada do GPCP para o período de 1979-2013 (coluna da esquerda) e simulada pelo QTCM (coluna do centro) para o período de 1979-2013. Viés da precipitação simulada pelo QTCM (mm.dia ${ }^{-1}$ ) (coluna da direita). 
Apesar da baixa resolução, o modelo tem habilidade para capturar os padrões sazonais médios climatológicos da precipitação sobre a América do Sul, mesmo apresentando baixos valores de precipitação na região da ZCIT sobre o Atlântico Tropical. Essa deficiência do QTCM na representação da intensidade e extensão da precipitação na região da ZCIT pode estar relacionada à parametrização de convecção, conforme sugerido por Sobel e Neelin (2006) e Lintner et al. (2012), que analisaram o desempenho do modelo considerando mudanças na camada limite atmosférica. A versão utilizada neste trabalho não leva em consideração a representação explícita da camada limite atmosférica.

Ainda, em relação à intensidade da precipitação, o modelo superestima a precipitação média sazonal sobre a Amazônia durante todas as estações, com viés variado de 2 a $3 \mathrm{~mm} \cdot \mathrm{dia}^{-1}$ durante os meses mais chuvosos (Tabela 2), consistente com os resultados de Zeng et al., 2000, que encontraram um viés positivo nessa região.

Os dados observados de precipitação têm forte influência da variabilidade interna intrínseca à própria atmosfera, e que não é totalmente reproduzida pelo QTCM. Essa omissão de alguns processos responsáveis por alguns tipos de variabilidade interna atmosférica no QTCM não garante uma perfeita concordância com a observação. Por outro lado, essa falta de "ruído" é uma vantagem para a análise dos processos e mecanismos de larga escala que o modelo representa. O nível geral de concordância entre os resultados do QTCM e as observações da precipitação é melhorado quando erros sistemáticos são removidos e para as regiões do Pacífico Equatorial e parte norte da Amazônia e nordeste do Brasil. A climatologia da precipitação tropical, em especial sobre estas duas regiões, embora imperfeita em relação às observações, parece capturar alguns padrões clássicos de distribuição de anomalias de precipitação associada ao ENOS, mesmo com uma baixa resolução espacial e habilidade de resolver um sistema menos complexo.

\subsection{Análises dos padrões de variabilidade interanual da precipitação}

Uma das principais finalidades do modelo QTCM é a simulação da variabilidade climática em escalas de tempo interanual. Na América do Sul, a variabilidade interanual da precipitação e o fluxo de umidade são influenciados pelos eventos ENOS no Pacífico Equatorial (Grimm, 2003 e 2004; Andreoli e Kayano, 2007; Andreoli et al., 2016) e pelo Modo Meridional do Atlântico (Andreoli e Kayano, 2007; Andreoli et al., 2012; Torralba et al., 2015), e, portanto, neste trabalho as análises consideram a atuação desses fenômenos em suas diferentes fases.

\subsubsection{Variabilidade interanual devido ao ENOS}

A fim de avaliar o padrão espacial da variabilidade interanual associado aos eventos ENOS ocorridos entre 1979 e 2013, são apresentados, nas Figs. 2 e 3, os campos compostos da diferença de precipitação entre os anos $E l$
Niño e La Niña (eventos quentes menos eventos frios), para DJF, MAM, JJA e SON, observados e simulados pelo QTCM, respectivamente.

A diferença dos compostos para o trimestre DJF mostrada pelo QTCM é de diferenças positivas (maiores que $4 \mathrm{~mm} \cdot \mathrm{dia}^{-1}$ ) na região do Pacífico Tropical, mais localizadas na porção Central e Oeste do oceano (Fig. 3a). Diferenças positivas também podem ser notadas sobre a América do Sul, cujas porções a Oeste e Sudoeste da Amazônia apresentam valores de até $2,5 \mathrm{~mm} \cdot \mathrm{dia}^{-1}$. Sobre as porções Leste da Amazônia e Nordeste Brasileiro, a diferença dos compostos mostra que o impacto do El Niño em reduzir a precipitação é mais intenso que o da La Niña em intensificar a precipitação. Este padrão sobre o Nordeste Brasileiro mostra-se mais intenso no QTCM (Fig. 3a) em comparação aos dados do GPCP (Fig. 2a). Na Amazônia os sinais da diferença dos compostos simulados são contrários à diferença dos compostos observados. O modelo QTCM também sugere redução mais intensa das chuvas na região da ZCIT sobre o oceano Atlântico Tropical, em anos de El Niño em comparação aos anos de La Niña, fato também verificado nos campos compostos observados.

Em MAM, a diferença dos compostos de precipitação simulada pelo QTCM sobre o Pacífico Tropical mostra-se com menores magnitudes e com menor extensão espacial (Fig. 3b), quando comparado ao equivalente composto das observações (Fig. 2b). Sobre a América do Sul, a configuração de diferenças negativas, entretanto, é confinada à região do litoral Norte, Nordeste Brasileiro (Fig. 3b), diferenciando-se do padrão observado do GPCP para esta estação, especialmente sobre a Amazônia (Fig. 2b).

A diferença dos compostos de precipitação simulada em JJA apresenta diferenças positivas e menores magnitudes em grande parte do oceano Pacífico, porém mais distribuídas espacialmente. No continente da América do Sul, o padrão de diferença simulado é apresentado de modo menos intenso, aproximando-se do padrão de diferença observado durante este trimestre, porém configurando reduções na região da ZCIT, desde a parte Norte da América do Sul até o oceano Atlântico Tropical (Fig. 3c).

Em SON, o QTCM sugere também diferenças positivas menos intensas sobre o Pacífico Tropical (em torno de 3 mm.dia ${ }^{-1}$ ) e com menor extensão espacial, apresentando núcleos de precipitação mais ajustados sobre a porção Oeste do oceano. O padrão de diferença é mantido sobre o continente, comparado ao do trimestre anterior (Fig. 3c), apresentando, inclusive, diferenças negativas $\left(-0,5 \mathrm{~mm} \cdot \mathrm{dia}^{-1}\right)$ desde a parte central da Amazônia até o Nordeste Brasileiro (Fig. 3d).

\subsubsection{Variabilidade devido ao $M M A$}

A diferença dos compostos de precipitação simulada associada à ocorrência de eventos MMA em DJF mostra diferenças negativas (impactos de eventos MMA- mais intensos que $\mathrm{MMA}+$ ) mais localizadas na porção Norte e Central do Atlântico Tropical (Fig. 5a), em concordância 

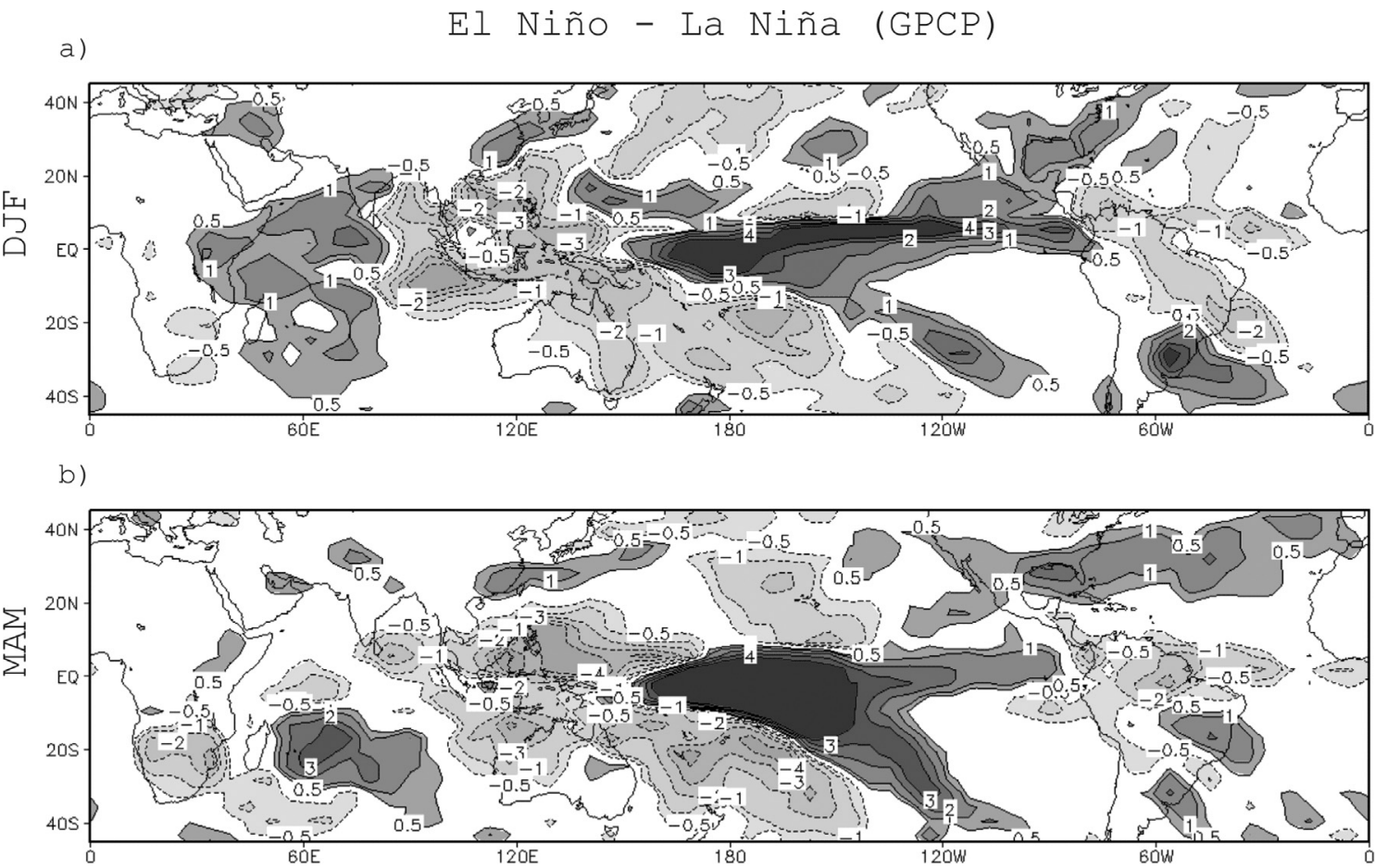

C)

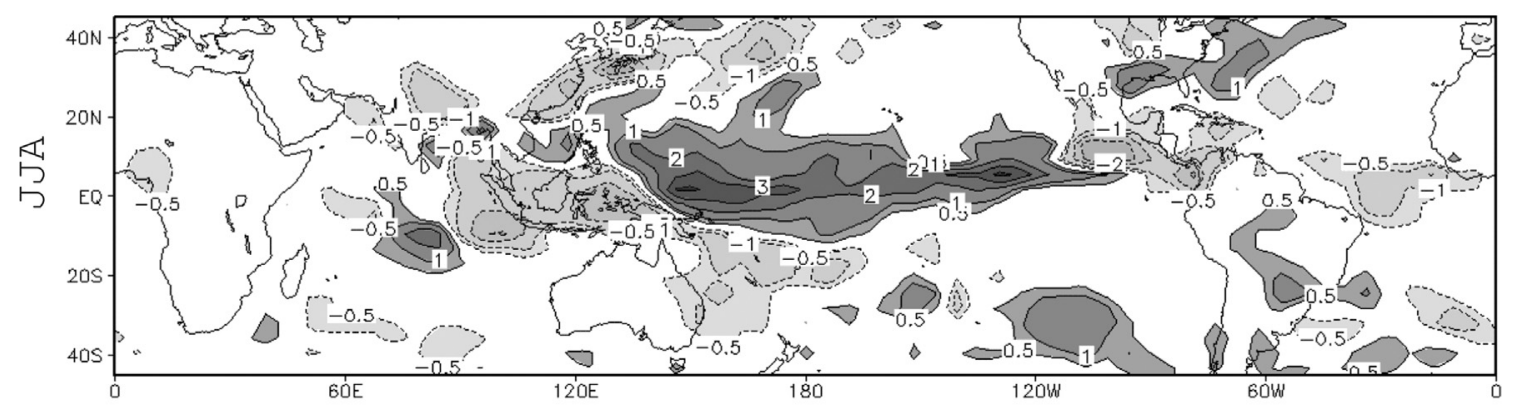

d)

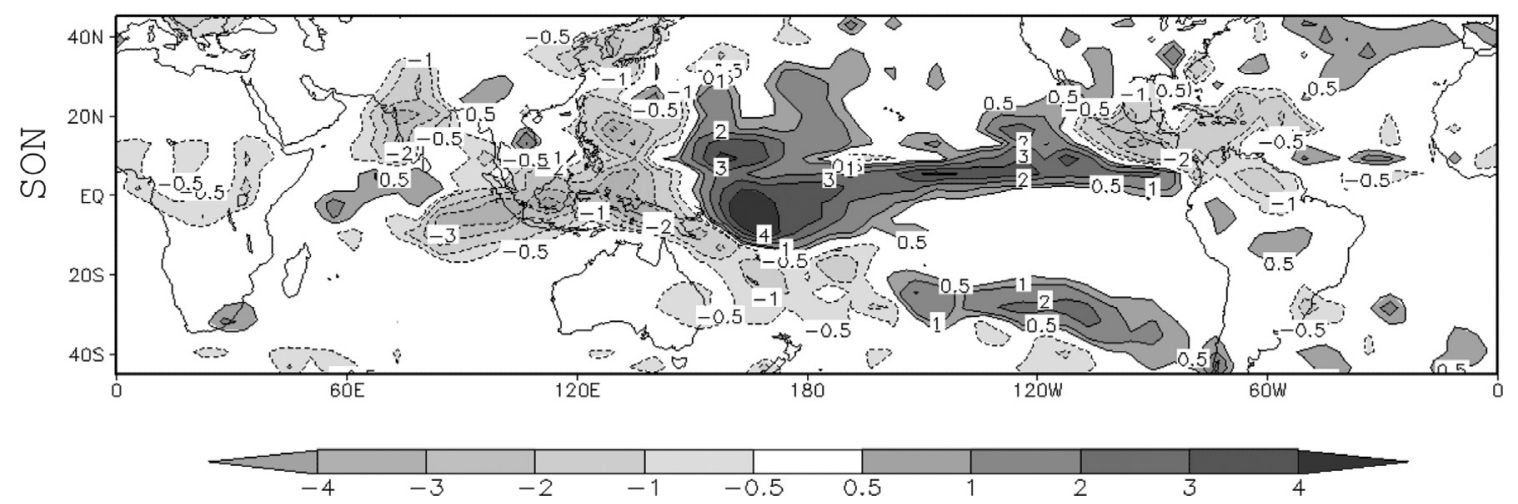

Figura 2 - Campos observados do GPCP da diferença de precipitação média sazonal (mm.dia ${ }^{-1}$ ) entre eventos quentes e frios de ENOS ocorridos entre 1979-2013.

com os dados do GPCP (Fig. 4a). Na região do Pacífico Tropical, configura-se um padrão longitudinal de diferenças positivas (negativas) na porção Central (Sudoeste) do oceano. Sobre a América do Sul, em grande parte do continente, os valores da diferença são simulados próximo ao observa- do, com exceção do Sul da América do Sul, onde a composição apresenta diferença de menores intensidades (Fig. 5a).

No trimestre MAM, a configuração do padrão da diferença dos compostos de precipitação tem posiciona- 
a) El Niño - La Niña (QTCM)

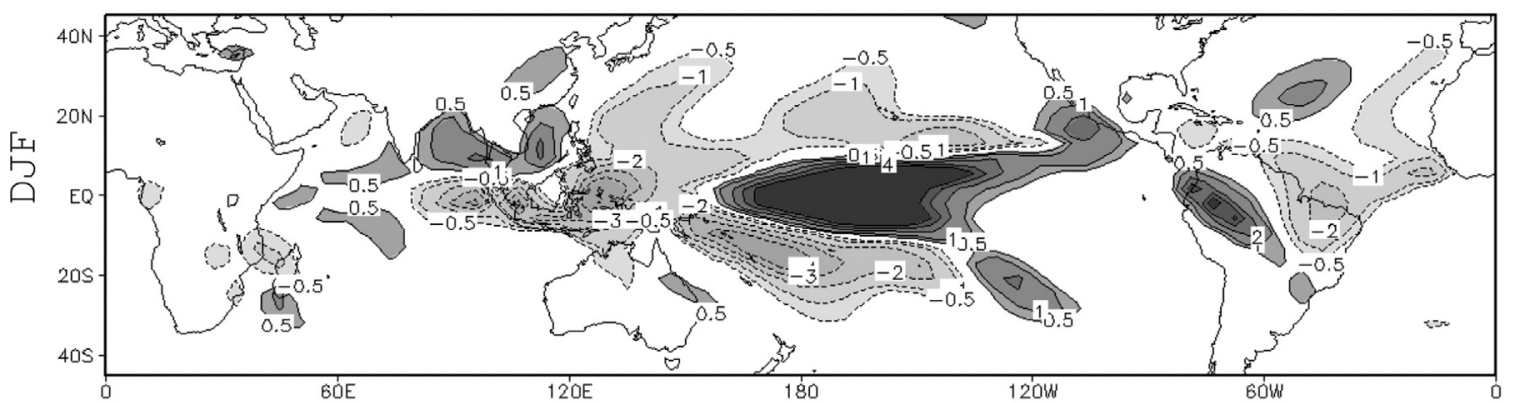

b)

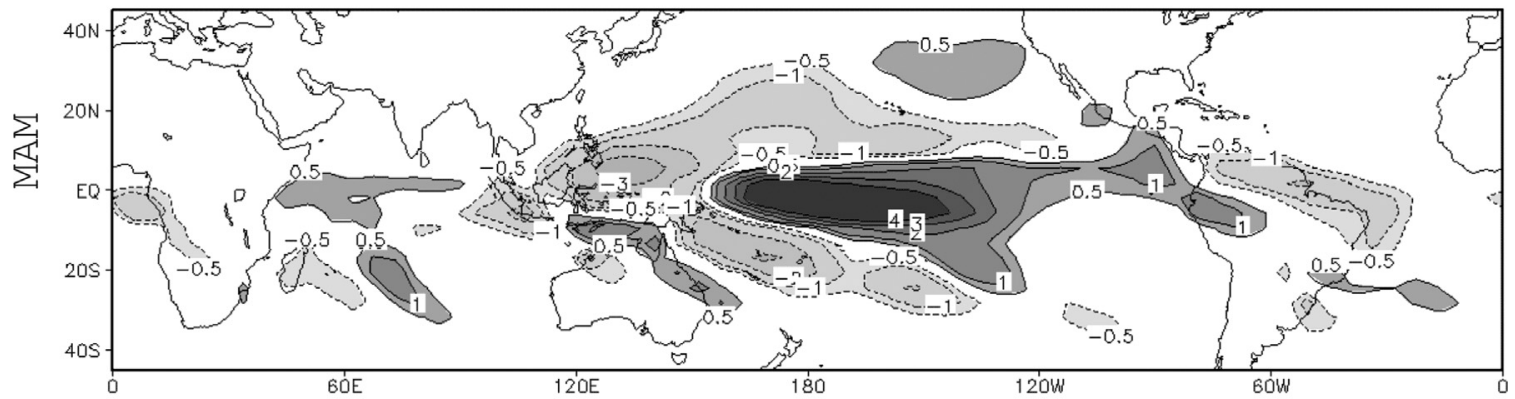

C)

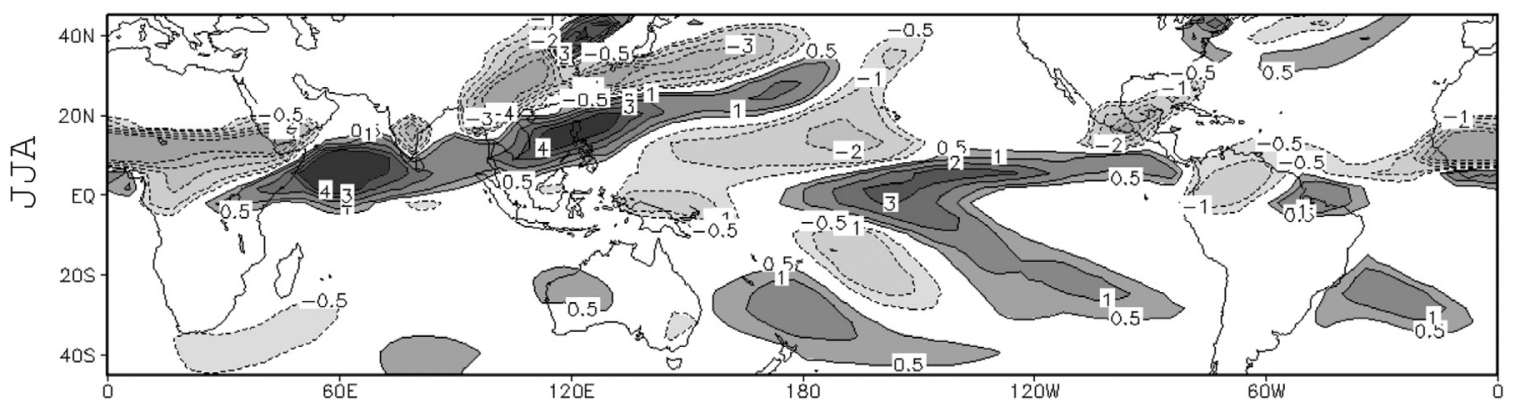

d)

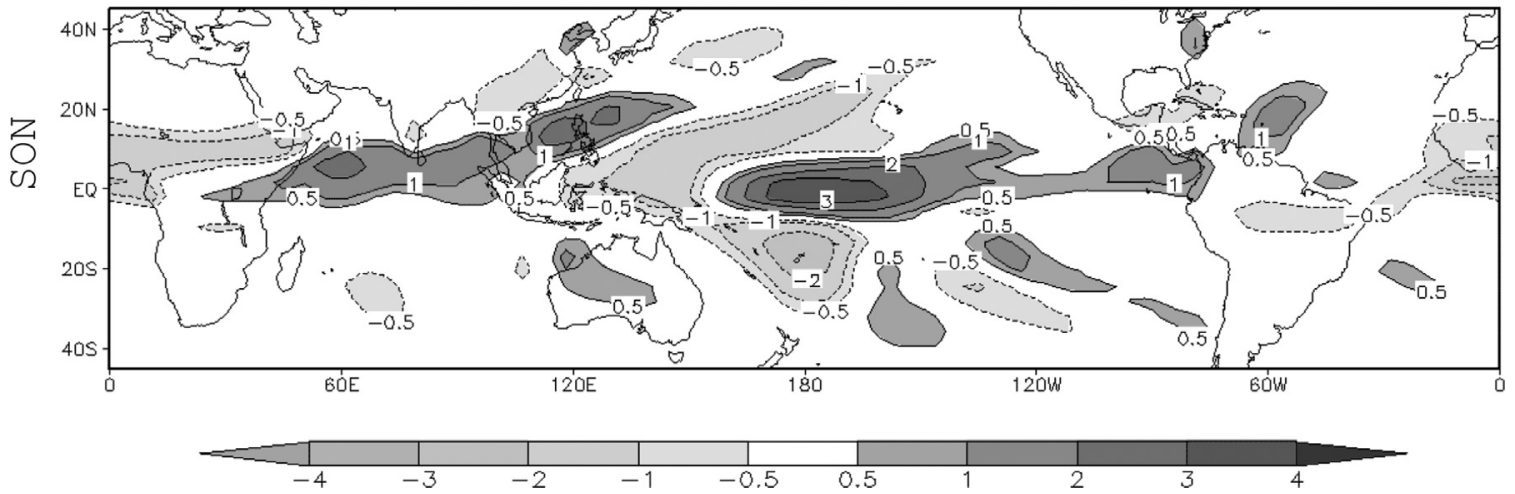

Figura 3 - Campos simulados pelo QTCM da diferença de precipitação média sazonal (mm.dia $\left.{ }^{-1}\right)$ entre eventos quentes e frios de ENOS ocorridos entre 1979-2013.

mento em direção ao oceano ATS, atingindo a região da ZCIT e partes da região Central e Sul da Amazônia, Nordeste Brasileiro e Sul do Brasil, apresentando, entretanto, diferença de sinal contrário na porção Norte da América do Sul. Sobre o Pacífico Tropical, o QTCM sugere um padrão oposto ao verificado na estação anterior (Fig. 5a) com diferenças negativas na porção Central e Leste do oceano, e positivas a Noroeste (Fig. 5b).

A diferença dos compostos de precipitação em JJA é mais intensa e positiva (negativa) sobre o ATN (região da 
ZCIT até o norte da América do Sul). Sobre o continente, o modelo simula aumento de chuva na porção Central da Amazônia e Sudeste do Brasil, diferentemente do padrão observado do GPCP (Fig. 4c).
A configuração da diferença dos compostos de precipitação durante SON é mais próxima do observado, sobre grande parte da América do Sul, apesar de apresentar diferenças positivas mais intensas no Nordeste Brasileiro e na região da ZCAS, enquanto que, sobre o Pacífico Tropical,

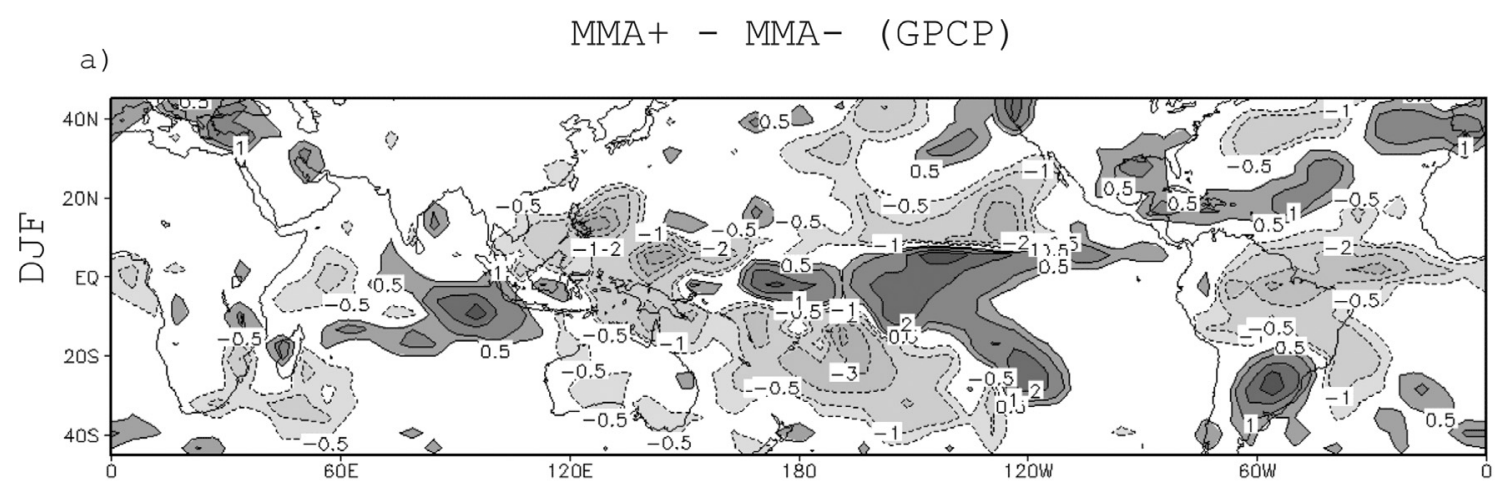

b)

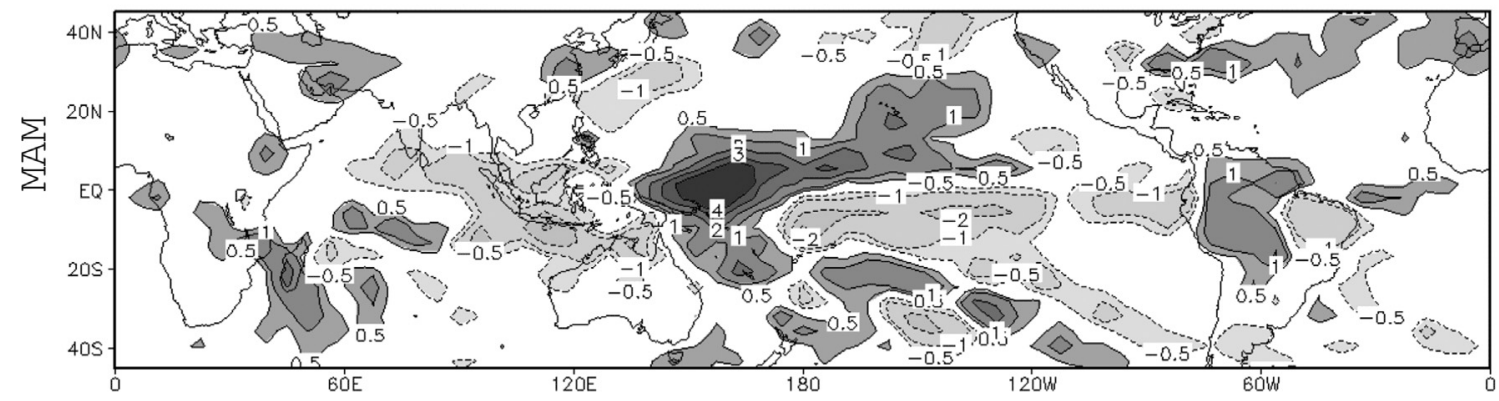

C)

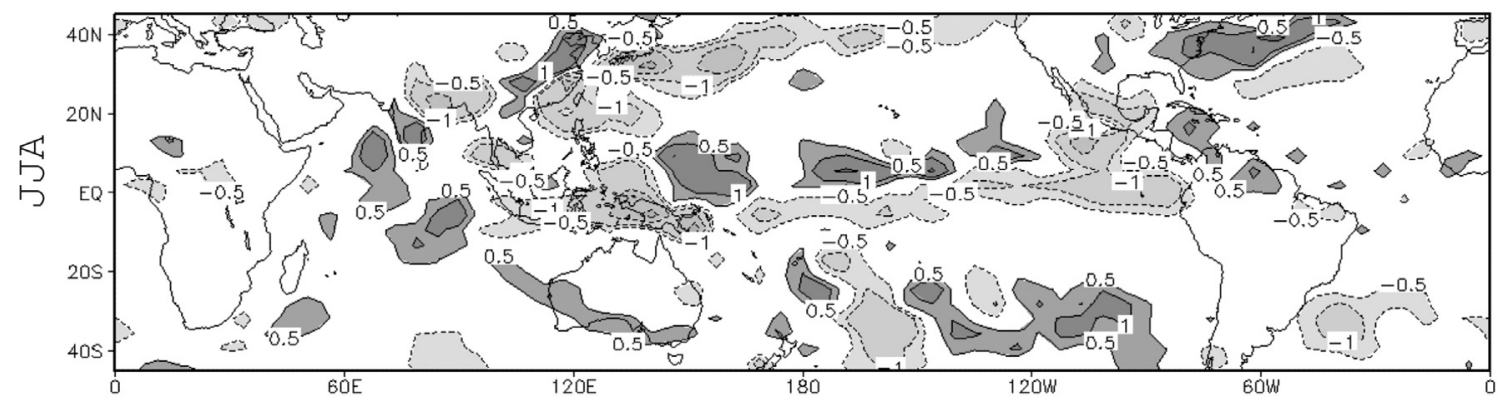

d)
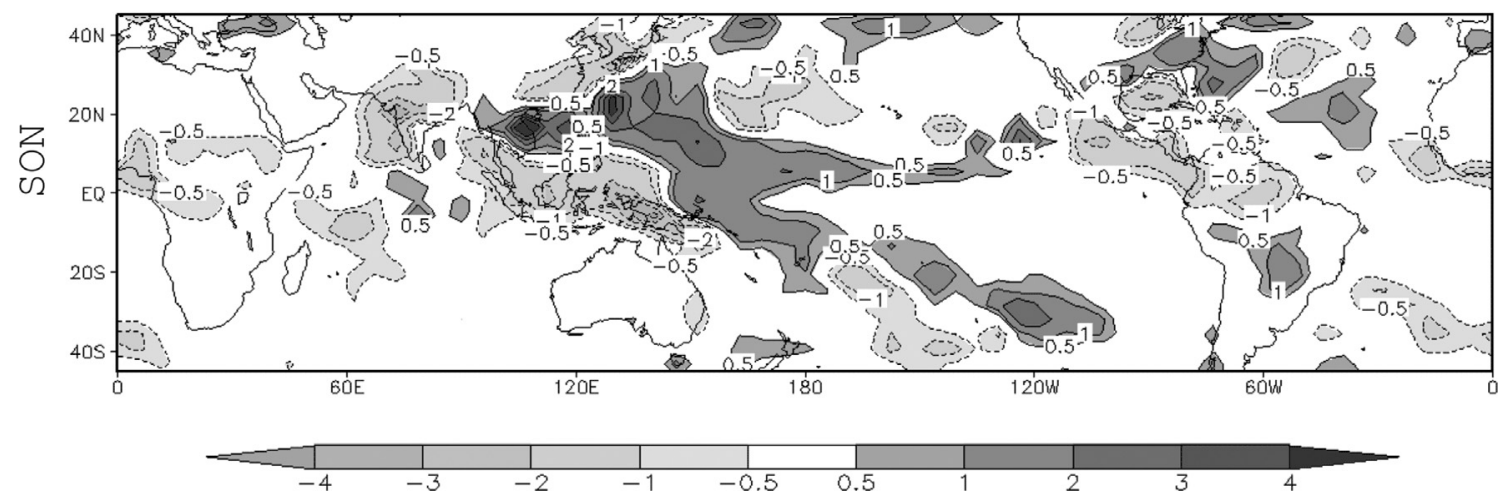

Figura 4 - Campos observados do GPCP da diferença de precipitação média sazonal (mm.dia ${ }^{-1}$ ) entre eventos quentes e frios de MMA ocorridos entre $1979-2013$ 
diferenças positivas são mais restringidas na porção Central e Oeste do oceano (Fig. 5d).

O modelo QTCM mostra-se promissor ao representar a variabilidade interanual da precipitação em relação aos fenômenos de grande escala, consistente com as condições oceânicas observadas, tais como o ENOS, em uma série mais longa de eventos, que apenas os três casos estudados por Zeng et al. (2000). No geral, o modelo consegue representar o deslocamento das diferenças negativas no setor norte da América do Sul, especialmente na região da ZCIT,

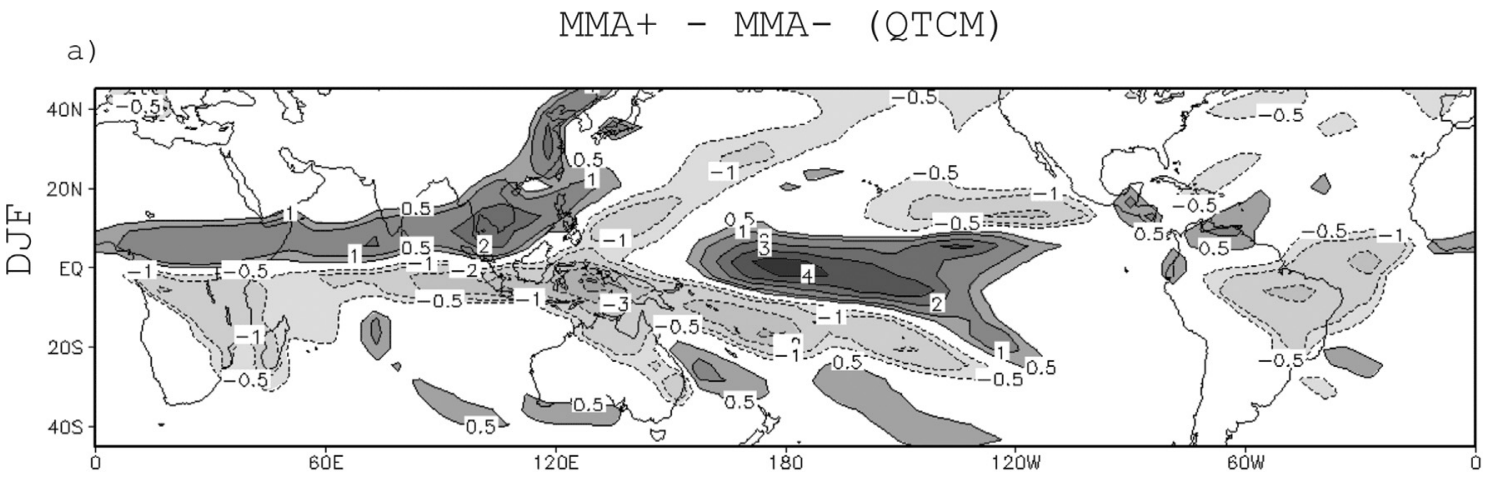

b)

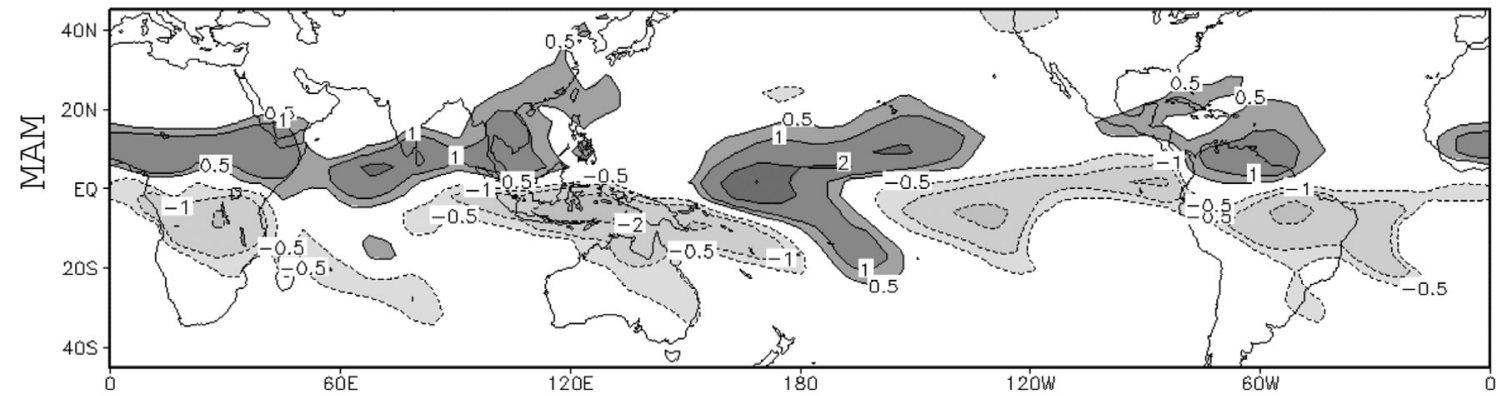

c)

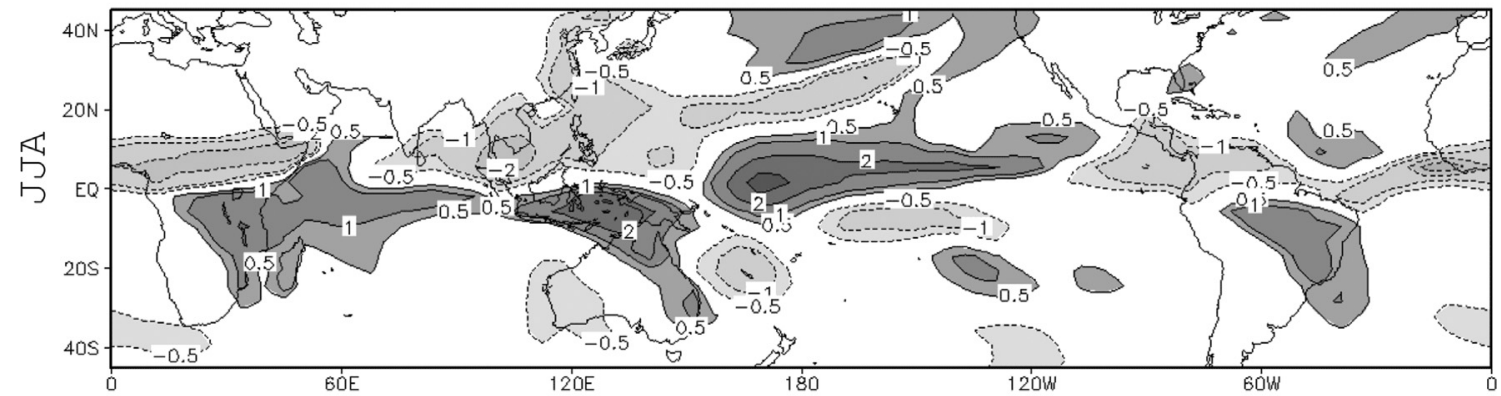

d)
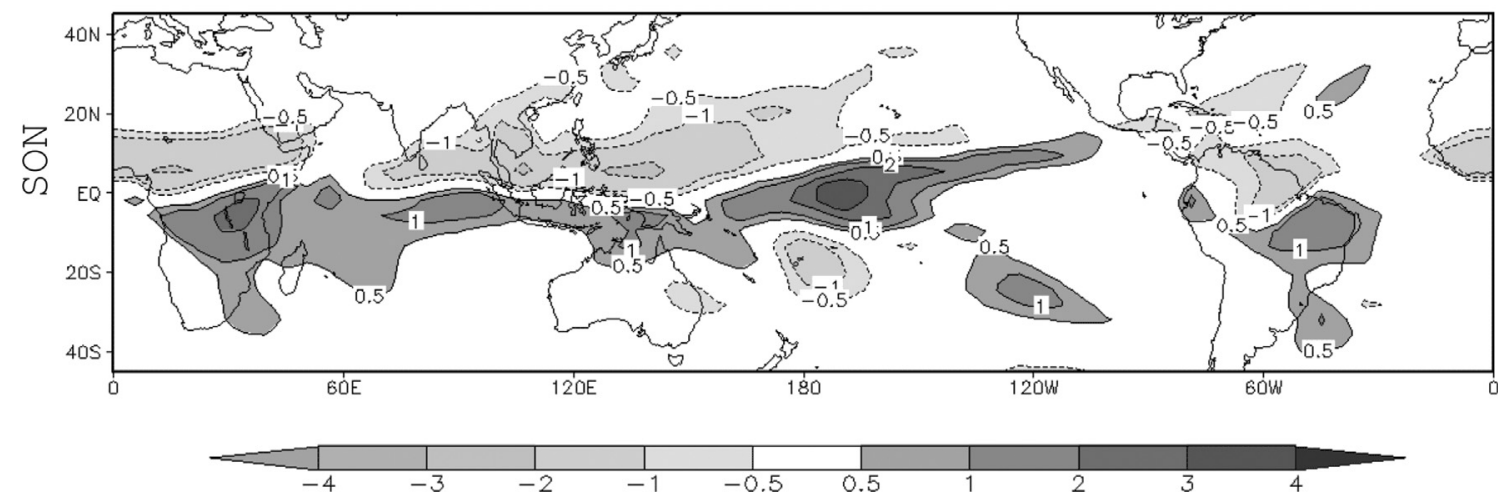

Figura 5 - Campos simulados pelo QTCM da diferença de precipitação média sazonal (mm.dia ${ }^{-1}$ ) entre eventos quentes e frios de MMA ocorridos entre $1979-2013$ 
representando bem melhor o padrão espacial daquelas diferenças observadas ao longo dos trimestres DJF e MAM, justamente quando o evento se encontra em sua fase madura. Nas estações de início e amadurecimento dos eventos, as respostas são mais bem representadas na região do oceano Pacífico, o que não é observado sobre o continente da América do Sul.

Adicionalmente, a análise da variabilidade da precipitação associada aos eventos MMA, incluídas neste estudo, mostram o potencial do modelo QTCM nos estudos idealizados também sobre o Atlântico Tropical. Apesar de ser um modelo de complexidade intermediária, o QTCM mostra-se capaz de avaliar, de forma incipiente, os processos físicos chave, envolvendo o clima da região tropical e sua associação com os padrões de TSM, relacionados ao ENOS e também ao Modo Meridional do Atlântico.

\subsection{Divergência do fluxo de umidade nos dados da Reanálise}

A influência dos padrões de TSM associados aos eventos ENOS e MMA no transporte de umidade para a
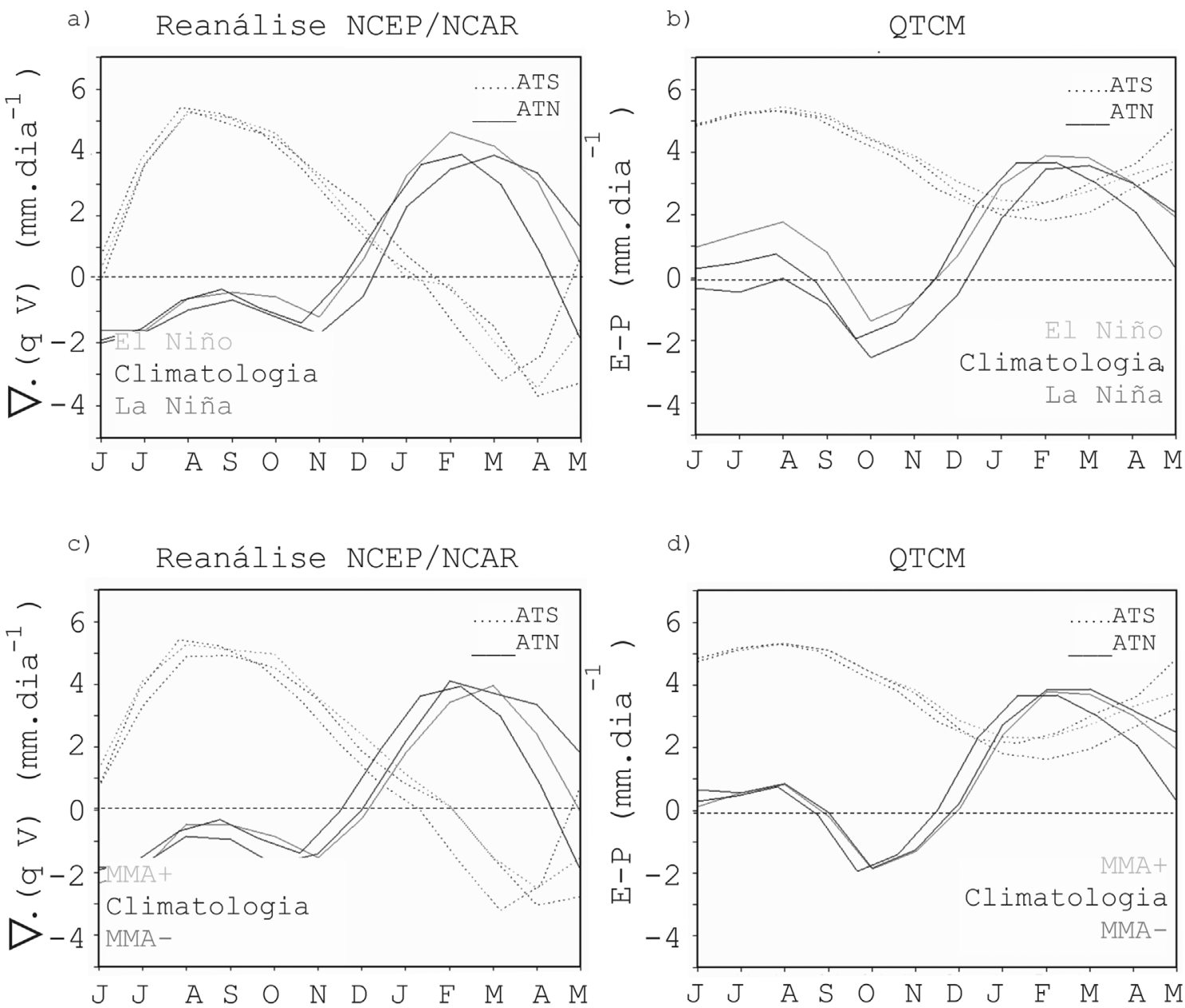

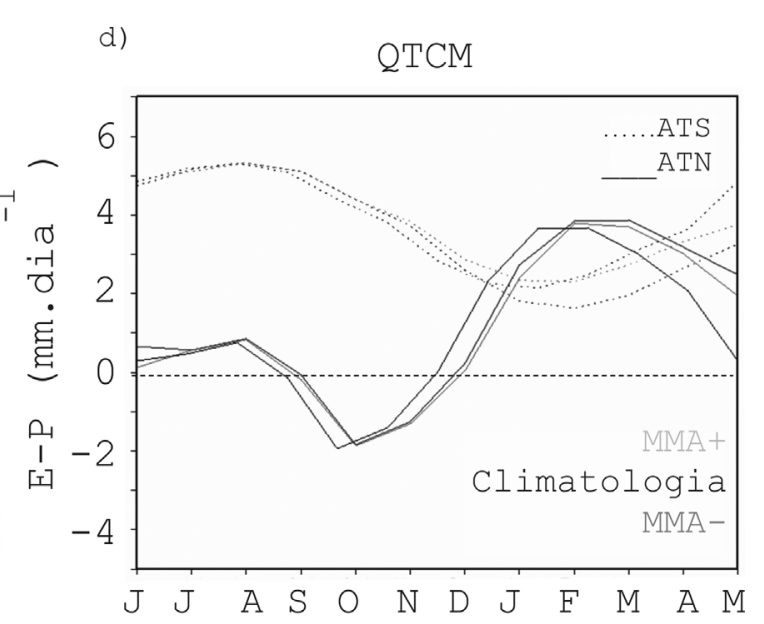

região tropical da América do Sul, através da DFU, é avaliada em comparação à climatologia, considerando as simulações do modelo QTCM e os dados de Reanálise. O objetivo aqui é verificar se o modelo QTCM representa as variações sazonais da DFU nas áreas do oceano Attântico Tropical (fonte de umidade para a atmosfera tropical) e na Amazônia (sumidouro de umidade continental) em associação a eventos ENOS e MMA.

\subsubsection{Análise sobre o Atlântico Tropical}

O comportamento do ciclo sazonal da DFU sobre as áreas oceânicas ATN e ATS (Fig. 6), e sobre a Amazônia (Fig. 7) é analisado considerando a composição de condições associadas a eventos ENOS e MMA, tanto nos dados da Reanálise (Figs. 6a, 6c, 7a e 7c) quanto nas simulações do QTCM (Figs. 6b, 6d, 7b e 7d). Na média climatológica da Reanálise, o ATN atua como fonte de umidade para a atmosfera (isto é, DFU $>0$ ) no período de dezembro a abril, com valores de máxima DFU nos meses de janeiro e fevereiro (Figs. 6a e 6c). Durante o inverno austral até meados de novembro, o ATN apresenta-se como sumidouro de umidade $(\mathrm{DFU}<0)$ (Figs. 6a e 6c). Nas mesmas figuras, a

Figura 6 - Ciclo anual da Divergência de Fluxo de Umidade (mm.dia ${ }^{-1}$ ) sobre os oceanos ATN e ATS, na ocorrência de eventos ENOS (a, b) e MMA (c, d), observados da Reanálise do NCEP/NCAR (coluna da direita) e simulados pelo QTCM (coluna da esquerda). 
contribuição climatológica do ATS nos dados da Reanálise, ocorre durante boa parte do ano e atinge o seu máximo na transição do inverno para a primavera austral, particularmente nos meses de agosto e setembro, quando a DFU sobre o ATS é maior. Durante o verão austral, a DFU sobre o ATS diminui até tornar-se negativa no mês de fevereiro (Figs. 6a e 6c). Esse padrão sazonal de DFU nas áreas do ATS é pouco modificado em anos de ENOS (El Niño, La Niña) e anos de MMA (MMA+, MMA-), na época em que esta área oceânica é fonte de umidade para atmosfera. No ATN os impactos do ENOS e MMA na DFU são mais evidentes. Durante eventos frios de ENOS (La Niña) a DFU é reduzida aos meses de dezembro a maio e sua contribuição como fonte de umidade para atmosfera é mais fraca que durante eventos quentes de ENOS (El Niño), quando a atuação ocorre de novembro a maio.

O ciclo sazonal da DFU em condições de MMA+, sobre o ATN, apresenta uma redução durante os meses de novembro a janeiro, entretanto durante os meses de fevereiro a maio a DFU tende a ser fortalecida. Em condições de MMA-, porém, observa-se também o enfraquecimento da DFU de julho até fevereiro, mas há uma intensificação mais
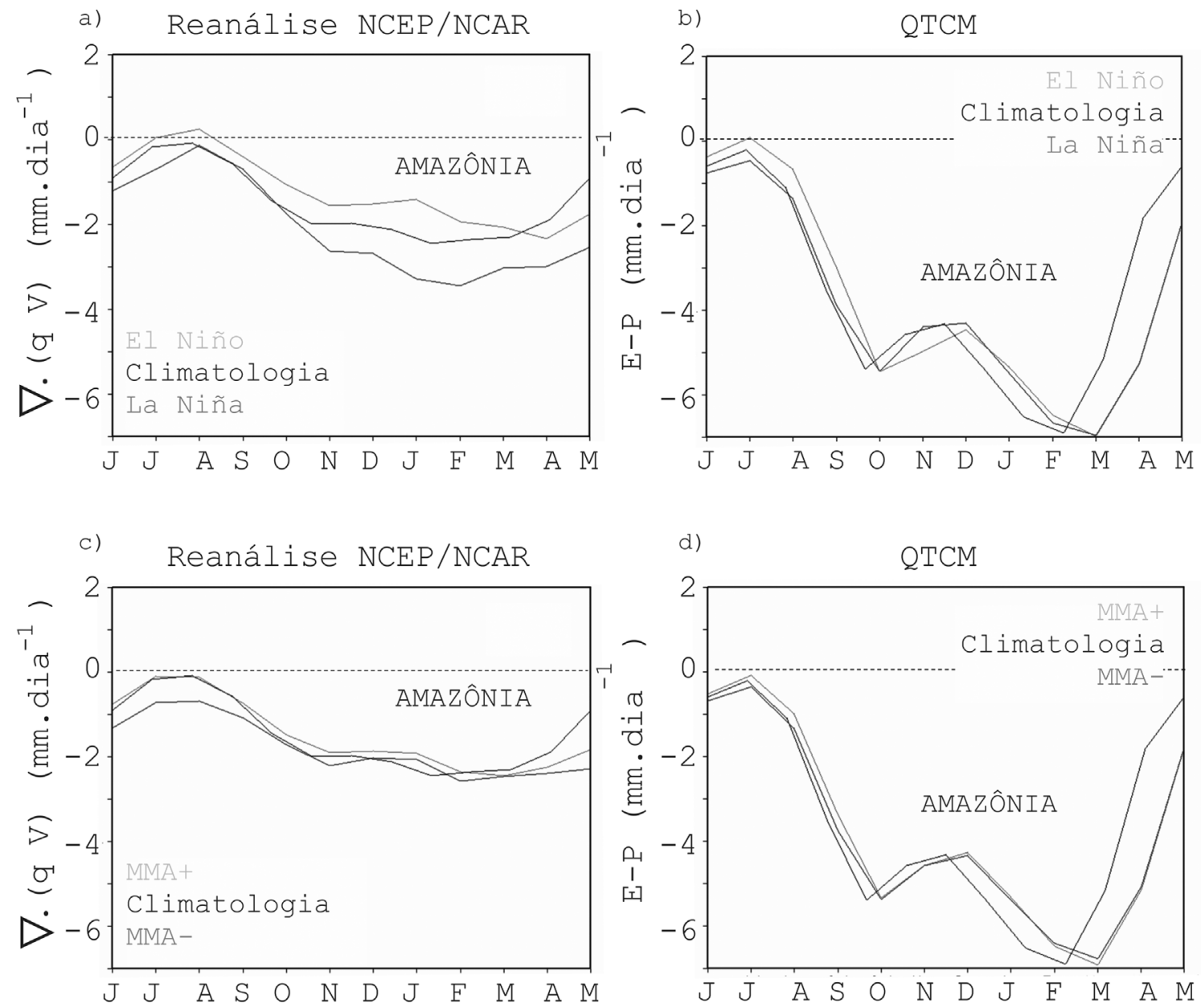

Figura 7 - Ciclo anual da Divergência de Fluxo de Umidade (mm.dia ${ }^{-1}$ ) sobre a Amazônia, na ocorrência de eventos ENOS (a, b) e MMA (c, d), observados da Reanálise do NCEP/NCAR (coluna da direita) e simulados pelo QTCM (coluna da esquerda). 
eventos frios de ENOS, principalmente nos meses de novembro a maio, a DFU torna-se mais negativa em comparação à climatologia (Fig. 7a), representando um aumento do fluxo de umidade para a região. Durante a ocorrência de eventos MMA, há uma menor variação, ou pouca influência das condições do MMA na DFU sobre a Amazônia, apesar de que durante MMA+ (MMA-) a DFU é menos (mais) negativa nos meses de novembro a fevereiro (junho a agosto) (Fig. 7c), indicando menor (maior) fluxo de umidade para a região nestes períodos.

\subsection{Divergência do fluxo de umidade simulado pelo QTCM}

A DFU obtida a partir das simulações com o modelo QTCM para as áreas oceânica e continental é também analisada em comparação com as estimativas dos dados da Reanálise. Na área do ATN a DFU apresenta valores mais elevados, ou seja, mostra-se fonte de umidade mais intensa em comparação a Reanálise associada à subestimativa da precipitação na região do Atlântico Tropical, fazendo com que a DFU seja mais positiva (Figs. 6b e 6d).

Semelhantemente aos dados da Reanálise, a média climatológica da DFU é fortalecida (enfraquecida) sobre o ATN, principalmente durante o verão (inverno) austral. Sobre o ATS, o modelo apresenta um ciclo sazonal com valores positivos durante todo o ano, com exceção dos meses de fevereiro a maio, cujos valores da DFU tornaram-se negativos (Figs. 6b e 6d). Na área do ATS (Fig. 6b), o modelo captura a influência do ENOS durante o verão austral, com a DFU fortalecida durante eventos quentes e enfraquecida durante eventos frios. Sobre o ATN o modelo sugere maiores influências do ENOS durante o inverno austral, com eventos La Niña (El Niño) fortalecendo (enfraquecendo) a DFU.

No caso dos eventos MMA, a DFU simulada pelo QTCM nas áreas do ATN e ATS apresenta comportamento semelhante aos resultados da Reanálise com menor sensibilidade que a indicada nos eventos ENOS. Além disso, o modelo sugere uma condição de fonte de umidade mais persistente no ATN (até maio). E, ao mesmo tempo em que é simulada uma condição persistente de fonte de umidade nos meses de fevereiro a maio no ATS (Fig. 6d), nos dados de Reanálise a região mostra-se como um sumidouro de umidade neste período do ano, condição que pouco se altera durante eventos de MMA (Fig. 6c). Sobre a Amazônia, o modelo QTCM sugere que a DFU se caracteriza como sumidouro de umidade durante todo o ano, recebendo máximas contribuições do ATN no mês de fevereiro e do ATS em julho (Fig. 7b), de maneira semelhante aos comportamentos obtidos com os dados da Reanálise (Fig. 7a). Nos meses de junho a outubro, em condições de ENOS, nota-se a maior influência no fornecimento de umidade oriunda dos oceanos, sobretudo em eventos quentes, quando a DFU é menos negativa (Fig. 7b). O QTCM também mostra que durante o período de JJA, na Amazônia, prevalece a condi- ção de fonte de umidade (DFU tende a valores positivos), de maneira semelhante aos resultados da Reanálise.

Na comparação entre os resultados da DFU da Reanálise e do QTCM sobre as áreas do oceano Atlântico Tropical, os padrões sazonais, magnitude e sensibilidade à ocorrência de eventos ENOS e MMA, mostram-se bastante semelhantes entre si, apesar do efeito dos erros sistemáticos na precipitação gerada pelo modelo. Entretanto, sobre a Amazônia, os resultados da variação sazonal da DFU diferem um pouco entre os conjuntos de dados analisados. Essa diferença ocorre em virtude da superestimativa da precipitação pelo modelo QTCM sobre a porção Norte do continente da América do Sul, o que explica o mínimo secundário na DFU entre os meses de setembro e novembro.

A variabilidade no transporte de umidade na região do ATN e do ATS está associada aos mesmos mecanismos que modulam a magnitude e confluência desses ventos, em que o papel do Atlântico Tropical, como a fonte remota de umidade, provavelmente está associado com a migração sazonal da ZCIT (Moura e Shukla, 1981; Drumond et al., 2014).

A variabilidade interanual da DFU parece originar-se a partir da dinâmica conduzida pelos ventos, cujos mecanismos associados às anomalias de TSM geram mudanças na circulação atmosférica sobre tais regiões oceânicas fontes de umidade (Gimeno et al., 2010, 2013; van der Ent et al., 2010; van der Ent e Savenije, 2013).

O comportamento médio sazonal da DFU nas áreas oceânicas do Atlântico Tropical, calculado com base nos resultados do QTCM, apresentam padrão similar aos apresentados por Drumond et al. (2014), mostrando que a condição de El Niño contribui para reduzir a precipitação, condição favorecida por uma DFU mais positiva. De maneira similar aos resultados de van der Ent e Savenije (2013) e Drumond et al. (2014), os resultados com um modelo simplificado como o QTCM também mostram a importância do oceano ATS no fornecimento de umidade para a bacia Amazônica em grande parte do ano, com exceção do verão austral, quando a contribuição do ATN é dominante.

\section{Conclusões}

Este estudo avalia através de um modelo mais simplificado dos processos físicos da atmosfera tropical, o QTCM, a influência das condições de ENOS e MMA na disponibilidade de umidade para a atmosfera das áreas dos oceanos ATN e ATS, e sobre o continente na região da Amazônia.

Os resultados encontrados com o QTCM mostram que o modelo consegue capturar razoavelmente bem a variabilidade interanual da precipitação em relação aos fenômenos de grande escala. O modelo destaca-se por representar a migração da atividade convectiva ao longo do ano, principalmente sobre o continente. Contudo, o padrão de precipitação associado à ZCIT, é timidamente represen- 
tado sobre o oceano durante SON, mas subestimado em DJF.

Os padrões de erros sistemáticos mostram que o modelo captura o padrão com vieses positivos exacerbado sobre o continente, gerando viés úmido dominante que se restringe ao norte da América do Sul e central da Amazônia, durante os meses DJF. Em contrapartida, um viés seco é visto nas outras áreas do continente, nas outras estações, com viés negativo mais intenso na região de confluência da ZCAS e regiões sul e sudeste do Brasil.

A representação do padrão de distribuição de precipitação em anos de ENOS pelo QTCM é capturada sobre a região do oceano Pacífico Equatorial, região em que o modelo está habilitado para representar os processos segundo sua física. Esse padrão durante os meses de verão é mais bem configurado que durante as demais estações. Sobre o continente, entretanto, surgem diferenças negativas (positivas) desde o extremo norte do continente e parte leste da Amazônia (nordeste do continente e central da Amazônia) até a região nordeste (Sul e Sudeste) do Brasil, configuração espacial que se difere das observações durante DJF.

Em eventos de MMA, o modelo captura bem os padrões de variabilidade interanual de precipitação sobre grande parte do continente, com um domínio de diferenças negativas na região central da Amazônia e nordeste do Brasil, avançando, inclusive, sobre o oceano Atlântico Tropical.

Com relação à divergência do fluxo de umidade sobre o oceano, o QTCM captura o padrão sazonal e temporal de fonte e sumidouro de umidade climatológico e sua variação com relação à ocorrência de eventos ENOS e MMA. Sobre a Amazônia, a DFU apresenta um período de máxima convergência que é coincidente com os dados da Reanálise ao longo do ano, porém em termos de magnitude é superestimada.

Com base no que foi discutido acima, os resultados das simulações com o QTCM em comparação com dados de Reanálise mostram que o modelo tem habilidade na reprodução dos padrões sazonais da precipitação continental e de sua variabilidade associadas aos eventos ENOS e MMA na região tropical, além de capturar a variação sazonal e interanual da Divergência do Fluxo de Umidade nas áreas oceânicas e no continente sobre a Amazônia, principalmente durante o verão austral, o que implica sua viabilidade de utilização em estudos idealizados do clima tropical.

\section{Agradecimentos}

Os autores agradecem ao Conselho Nacional de Desenvolvimento Científico e Tecnológico $(\mathrm{CNPq})$ pelo suporte a pesquisa (Projeto N. 485344/2013-0). O terceiro autor foi parcialmente financiado pelo CNPq (Processo N. 305942/2015-8). Os autores agradecem também ao CNPq pela bolsa de mestrado cedida ao primeiro autor e aos revisores anônimos.

\section{Referências}

ADLER, R.F.; HUFFMAN, G.; CHANG, A.; FERRARO, R.; XIE, P.; JANOWIAK, J.; RUDOLF, B.; SCHNEIDER, U.; CURTIS, S.; BOLVIN, D.; GRUBER, A.; SUSSKIND, J.; ARKIN, P. The Version 2 Global Precipitation Climatology Project (GPCP) Monthly Precipitation Analysis (1979Present). Journal of Hydrometeorology, v. 4, p. 1147 1167, 2003.

ANDREOLI, R.V.; KAYANO, M.T. A importância relativa do Atlântico Tropical Sul e Pacífico Leste na variabilidade de precipitação do nordeste do Brasil. Revista Brasileira de Meteorologia, v. 22, n. 1, p. 63-74, 2007.

ANDREOLI, R.V.; OLIVEIRA, S.S.; KAYANO, M.T.; VIEGAS, J.; SOUZA, R.A.F.; CANDIDO, L.A. The influence of diferent El Niño types on the South American rainfall. International Journal of Climatology, v. 37, p. 1374-1390, 2016.

ANDREOLI, R.V.; SOUZA, R.A.F.; KAYANO, M.T.; CANDIDO, L.A. Seasonal anomalous rainfall in the central and eastern Amazon and associated anomalous oceanic and atmospheric patterns. International Journal of Climatology, v. 30, p. 1193-1205, 2012.

BETTS, A.K.; MILLER, M.J. A new convective adjustment scheme. Part II: Single column tests using GATE wave, BOMEX, ATEX and arctic air-mass data sets. Quarterly Journal of the Royal Meteorological Society, v. 112, p. 693-709, 1986.

CHEN, J.L.; WILSON, C.R.; TAPLEY, B.D.; YANG, Z.L.; NIU, G.Y. 2005 drought event in the Amazon River basin as measured by GRACE and estimated by climate models. Journal of Geophysical Research, v. 114, B05404, 2009.

CHIANG, J.C.H.; SOBEL, A.H. Tropical tropospheric temperature variations caused by ENSO and their influence on the remote tropical climate. Journal of Climate, v. 15, p. 2616-2631, 2002.

CHOU, C.; NEELIN, J.D. Linearization of a longwave radiation scheme for intermediate tropical atmospheric models. Journal of Geophysical Research, v. 101, p. 15129-15145, 1996.

DIAZ, A.F.; STUDZINSKI, C.D.S. Rainfall anomalies in the Uruguay-Southern Brazil region related to SST in the Pacific and Atlantic Oceans using canonical correlation analysis. Em: Congresso Brasileiro de Meteorologia, 8., Congresso Latino-Americano de Meteorologia, 2., Belo Horizonte, 1994. Anais. São José dos Campos: INPE. v.1, p. 498-501.

DRUMOND, A.; MARENGO, J.; AMBRIZZI, T.; NIETO, R.; MOREIRA, L.; GIMENO, L. The role of the Amazon Basin moisture in the atmospheric branch of the hydrological cycle: a Lagrangian analysis. Hydrology and Earth System Science, v. 18, p. 2577-2598, 2014.

DRUMOND, A.; NIETO, R.; GIMENO, L.; AMBRIZZI, T. A Lagrangian identification of major sources of moisture over Central Brazil and La Plata Basin. Journal Geophysical Research, v. 113, D14128, 2008.

ESPINOZA, J.C.; RONCHAIL, J.; GUYOT, J.L.; JUNQUAS, C.; VAUCHEL, P.; LAVADO, W.; DRAPEAU, G.; POMBOSA, R. Climate variability and extreme drought in the upper Solimões River (Western Amazon Basin): understanding the exceptional 2010 drought. Geophysical Research Letters, v. 38, L13406, 2011. 
ENFIELD, D.B.; MAYER, D.A. Tropical Atlantic sea surface temperature variability and its relation to El Niño-Southern Oscillation. Journal of Geophysical Research, v. 102, p. 929-945, 1997.

GIMENO, L.; DRUMOND, A.; NIETO, R.; TRIGO, R.M.; STOHL, A. On the origin of continental precipitation. Geophysical Research Letters, v. 37, L13804, 2010.

GIMENO, L.; NIETO, R.; DRUMOND, A.; CASTILLO, R.; TRIGO, R. Influence of the intensification of the major oceanic moisture sources on continental precipitation. Geophysical Research Letters, v. 40, p. 1443-1450, 2013.

GIMENO, L.; STOHL, A.; TRIGO, R.M.; DOMINGUEZ, F.; YOSHIMURA, K.; YU, L.; DRUMOND, A.; DURÁNQUESADA, A.M.; NIETO, R. Oceanics and terrestrial sources of continental precipitation. Reviews of Geophysics, v. 50, RG4003, 2012.

GUSHCHINA, D.; DEWITTE, B.; ILLIG, S. Remote ENSO forcing $v s$. local air-sea interaction in QTCM: a sensitivity study to intraseasonal variability. Advances in Geosciences, v. 6, p. 289-297, 2006.

HOERLING, M.P.; KUMAR, A.; ZHONG, M. El Niño, La Niña, and the nonlinearity of their teleconnections. Journal of Climate, v. 10, p. 1769-1785, 1997.

GRIMM, A.M. The El Niño impact on the summer monsoon in Brazil: regional processes $v s$. remote influences. Journal of Climate, v. 16, p. 263-280, 2003.

GRIMM, A.M. How do La Niña events disturb the summer monsoon system in Brazil? Climate Dynamics, v. 22, p. 123138, 2004.

GRIMM, A.M.; ZILLI, M.T. Interannual variability and seasonal evolution of summer monsoon rainfall in South America. Journal of Climate, v. 22, p. 2257-2275, 2009.

KALNAY, E.; KANAMITSU, M.; KISTLER, R.; COLLINS, W.; DEAVEN, D.; GANDIN, L.; IREDELL, M.; SAHA, S.; WHITE, G.; WOOLLEN, J.; ZHU, Y.; LEETMAA, A.; REYNOLDS, R.; JENNE, R.; JOSEPH, D. The NCEP/NCAR 40-year reanalysis project, Bulletin of the American Meteorological Society, v. 77, n. 3, p. 437-470, 1996.

KAYANO, M.T.; RAO, V.B.; ANDREOLI, R.V. A review of short-term climate variability mechanisms. Advances in Space Research, v. 35, p. 843-851, 2005.

KAYANO, M.T.; ANDREOLI, R.V.; SOUZA, R.A.F. Evolving anomalous SST patterns leading to ENSO extremes: relations between the tropical Pacific and Atlantic Oceans and the influence on the South American rainfall. International of Journal Climatology, v. 31, p. 1119-1134, 2011.

KAYANO, M.T.; ANDREOLI, R.V.; SOUZA, R.A.F. Relations between ENSO and South Atlantic SST modes and their effects on the South American rainfall. International Journal of Climatology, v. 33, p. 2008-2023, 2013.

KOUSKY, V.E.; KAGANO, M.T.; CAVALCANTI, I.F.A. A review of the Southern Oscillation-oceanic-atmospheric circulation changes and related rainfall anomalies. Tellus, v. 36A, p. 490-504, 1984.

LEWIS, S.L.; BRANDO, P.M.; PHILLIPS, O.L.; van der Heijden, G.M.F.; Nepstad, D. The 2010 Amazon drought. Science, v. 331, p. 554, 2011.

LIEBMANN, B.; MARENGO, J.A. Interannual variability of the rainy season and rainfall in the Brazilian Amazon basin. Journal of Climate, v. 14, p. 4308-4318, 2001.
LINTNER, B.R.; BELLON, G.; SOBEL, A.H.; KIM, D.; NEELIN, J.D. Implementation of the Quasi-equilibrium Tropical Circulation Model2 (QTCM2): global simulations and convection sensitivity to free tropospheric moisture. Journal of Advances in Modeling Earth Systems, v. 4, M12002, 2012.

LINTNER, B.R.; CHIANG, J.C.H. Adjustment of the remote tropical climate to El Niño conditions. Journal of Climate, v. 20, p. 2544-2557, 2007.

Marengo, J.A.; Alves, L.M.; Soares, W.R.; Rodriguez, D.A.; Camargo, H.; Riveros, M.P.; Pabló, A.D. Two contrasting severe seasonal extremes in Tropical South America in 2012: flood in Amazonia and drought in Northeast Brazil. Journal of Climate, v. 26, p. 9137-9154, 2013.

MARENGO, J.A.; DIAS, P.S. Mudanças climáticas globais e seus impactos nos recursos hídricos. Em: Rebouças, A.C.; Braga, B.; Tundisi, J.G. (Ed.) Águas doces no Brasil: capital ecológico, uso e conservação. 3. ed. São Paulo: Instituto de Estudos Avançados da USP, Academia Brasileira de Ciências, p. 63-109. 2006.

MARENGO, J.A.; NOBRE, C.A.; TOMASELLA, J.; CARDOSO, M.F.; OYAMA, M.D. Hydro-climatic: and ecological behaviour of the drought of Amazonia in 2005. Philosophical Transactions of the Royal Society B., v. 363, p. 17731778, 2008a.

MARENGO, J.A.; NOBRE, C.A.; TOMASELLA, J.; OYAMA, M.D.; OLIVEIRA, G.S.; OLIVEIRA, R.; CAMARGO, H.; ALVES, L.M.; BROWN, I.F. The drought of Amazonia in 2005. Journal of Climate, v. 21, p. 495-516, 2008b.

MARSHALL, J.; KUSHNER, Y.; BATTISTI, D.; CHANG, P.; CZAJA, A.; DICKSON, R.; HURRELL, J.; MCCARTNEY, M.; SARAVANAN, R.; VISBECK, M. North Atlantic climate variability: phenomena, impacts and mechanisms. International Journal of Climatology, v. 21, p. 1863-1898, 2001.

MOURA, A.D.; SHUKLA, J. On the dynamics of droughts in northeast brazil: observations, theory and numerical experiments with a general circulation model. Journal of the Atmospheric Sciences, v. 38, p. 2653-2675, 1981.

NEELIN, J.; SU, H. Moist teleconnection mechanisms for the tropical South American and Atlantic sector. Journal of Climate, v. 18, p. 3928-3950, 2005.

NEELIN, J.D.; ZENG, N. A Quasi-equilibrium Tropical Circulation Model: formulation. Journal of the Atmospheric Sciences, v. 57, p. 1741-1766, 2000.

NOBRE, P.; SHUKLA, J. Variations of sea surface temperature, wind stress, and rainfall over the tropical Atlantic and South America. Journal of Climate, v. 9, p. 2464-2479, 1996.

RONCHAIL, J.; COCHONNEAU, G.; MOLINIER, M.; GUYOT, J.L.; CHAVES, A.G.D.M.; GUIMARAES, V.; OLIVEIRA, E. Interannual rainfall variability in the Amazon basin and sea surface temperatures in the equatorial $\mathrm{Pa}-$ cific and the tropical Atlantic Oceans. International Journal of Climatology, v. 22, p. 1663-1686, 2002.

SATYAMURTY, P.; COSTA, C.P.W.; MANZI, A.O. Moisture source for the Amazon Basin: a study of contrasting years. Theoretical and Applied Climatology, v. 111, p. 195-209, $2013 \mathrm{a}$.

SATYAMURTY, P.; COSTA, C.P.W.; MANZI, A.O.; CANDIDO, L.A. A quick look at the 2012 record flood in 
the Amazon Basin. Geophysical Research Letters, v. 40, p. 1396-1401, 2013b.

SERVAIN, J. Simple climatic indices for the tropical Atlantic Ocean and some applications. Journal of Geophysical Research, v. 96, p. 15137-15146, 1991.

SMITH, T.; REYNOLDS, R.; PETERSON, T.; LAWRIMORE, J. Improvements to NOAA's historical merged land-ocean surface temperature analysis (1880-2006). Journal of Climate, v. 21, p. 2283-2296, 2008.

SOBEL, A.H.; NEELIN, J.D. The boundary layer contribution to intertropical convergence zones in the quasi-equilibrium tropical circulation model framework. Theoretical and Computational Fluid Dynamics, v. 20, p. 323-350, 2006.

SU, H.; NEELIN, J.D. Teleconnection mechanisms for tropical Pacific descent anomalies during El Niño. Journal of the Atmospheric Sciences, v. 59, p. 2694-2712, 2002.

TORRALBA, V.; RODRÍGUEZ-FONSECA, B.; MOHINO, E.; LOSADA, T. The non-stationary influence of the Atlantic and Pacific Niños on North Eastern South American rainfall. Frontiers in Earth Science, v. 3, p.55, 2015.

TRENBERTH, K.E. The definition of El Niño. Bulletin of the American Meteorological Society, v. 78, p. 2771-2777, 1997.

TRENBERTH, K.E.; FASULLO, J.T.; MACKARO, J. Atmospheric moisture transports from ocean to land and global energy flows in reanalyses. Journal of Climate, v. 24, p. 4907-4924, 2011.
UVO, C.B.; TÖLLE, U.; BERNDTSSON, R. Forecasting discharge in Amazonia using artificial neural networks. International Journal of Climatology, v. 20, p. 1495-1507, 2000.

VAN DER ENT, R.J.; SAVENIJE, H.H.G. Oceanic sources of continental precipitation and the correlation with sea surface temperature. Water Resources Research, v. 49, p. 39934004, 2013.

VAN DER ENT, R.J.; SAVENIJE, H.H.G.; SCHAEFLI, B.; STEELE-DUNNE, S.C. Origin and fate of atmospheric moisture over continents. Water Resources Research, v. 46, W09525, 2010.

YOON, J.H.; ZENG, N. An Atlantic influence on Amazon rainfall. Climate Dynamics, v. 34, p. 249-264, 2010.

ZENG, N. Seasonal cycle and interannual variability in the Amazon hydrologic cycle. Journal of Geophysical Research, v. 104, n. D8, p. 9097-9106, 1999.

ZENG, N.; YOON, J.H.; MARENGO, J.A.; SUBRAMANIAM, A.; NOBRE, C.A.; MARIOTTI, A.; NEELIN, J.D. Causes and impacts of the 2005 Amazon drought. Environmental Research Letters, v. 3, n. 1, 014002, 2008.

ZENG, N.; NEELIN, J.D.; CHOU, C. A Quasi-equilibrium Tropical Circulation Model: implementation and simulation. Journal of the Atmospheric Sciences, v. 57, p. 1767-1796, 2000.

This is an Open Access article distributed under the terms of the Creative Commons Attribution Non-Commercial License which permits unrestricted non-commercial use, distribution, and reproduction in any medium provided the original work is properly cited. 